\title{
Who Falls in Love With a Narcissist? Testing Women's Romantic Attraction Towards Fictional Male Characters
}

\author{
Lisa M. W. Vos ${ }^{1}$, Iris Frowijn², and Manon A. van Scheppingen² \\ ${ }^{1}$ Department of Medical and Clinical Psychology, Tilburg University \\ 2 Department of Developmental Psychology, Tilburg University
}

\section{Author Note}

This is a non-peer reviewed preprint.

The authors report no conflicts of interests.

This research received no specific grant from any funding agency in the public, commercial, or not-for-profit sectors.

Correspondence concerning this article should be addressed to Lisa Vos, Department of Medical and Clinical Psychology, Warandelaan 2, room T519, Tilburg University, 5037AB Tilburg, the Netherlands. E-mail: L.M.W.Vos@gmail.com

We would like to express our sincere gratitude to Dr. Carlo Garofalo, whose insightful comments and suggestions were invaluable in finalizing the manuscript. 


\begin{abstract}
The present research examined whether women's narcissistic traits, thrill-seeking, impulsivity, and attachment style are associated with their level of attraction towards narcissistic men. Two trait dimensions of narcissism were distinguished: admiration (i.e., promoting oneself to gain admiration) and rivalry (i.e., devaluing others to protect one's selfview). Participants (195 heterosexual women, $M_{\text {age }}=20.78, S D=2.40$ ) were asked to rate their level of attraction towards 25 pictures of fictional male characters who score relatively high or low on narcissism. Using multilevel modelling, we found that women were more attracted to men with high levels of narcissistic admiration (vs. low), and less attracted towards men with high scores on narcissistic rivalry (vs. low). We found no evidence that women who scored high on narcissism were more attracted to narcissistic men. Response surface analyses revealed that women who scored high on thrill-seeking (vs. low) were more attracted to narcissistic admiration, and to a lesser extent to narcissistic rivalry. Additionally, we discovered that women who scored high on impulsivity or avoidant attachment (vs. low) were (to a small extent) more attracted to narcissistic rivalry. Identifying women who are attracted to narcissistic men can help to implement and improve prevention or intervention programs related to narcissism in romantic relationships.
\end{abstract}

Keywords: Romantic attraction, narcissism, thrill-seeking, impulsivity, attachment, multilevel response surface analysis 


\section{Who Falls in Love With a Narcissist? Testing Women's Romantic Attraction Towards Fictional Male Characters}

Falling for a narcissist can be easy-they can be good-looking, charming, intelligent, and humorous. Though, the development of an intimate long-term relationship with a narcissist is rather challenging. Indeed, narcissism is negatively associated with interpersonal romantic behavior, such as being agreeable, feeling empathy, perspective-taking, and showing intimacy (Campbell, 1999). Accordingly, narcissism predicts several relationship dysfunctions such as relationship dissatisfaction, lack of commitment, infidelity, and manipulative gameplaying (Campbell, Foster, et al., 2002; Wurst et al., 2017). Overall, narcissistic individuals tend to make bad romantic partners. Knowing this, why are some women still attracted to these "darker personalities"?

\section{Grandiose Narcissism}

From a clinical perspective, narcissism can be seen as a personality disorder, which refers to a pathological form of self-importance that involves grandiose fantasies, arrogant attitudes, and lack of empathy (i.e., narcissistic personality disorder [NPD]; American Psychiatric Association, 2013; Miller et al., 2012). In our research, however, the focus is on grandiose narcissism. Grandiose narcissism (henceforth referred to as narcissism) can be viewed as a personality trait that occurs in the general population rather than only in clinical populations (Back et al., 2013). Individuals high on narcissism consider themselves as unique and superior to others (Campbell, Foster, et al., 2002; Miller et al., 2011). They maintain their grandiose self-views by seeking attention and admiration from others (Back et al., 2013). To express their need for admiration, they behave in charming, self-assured, and dominant ways (Back et al., 2013; Back et al., 2010; Campbell \& Campbell, 2009). On the other hand, they protect their grandiose self-views by devaluing others, resulting in aggressive, arrogant, and egocentric behaviors (Back et al., 2013; Campbell et al., 2005). Recently, two trait dimensions of narcissism were identified, explaining the paradoxical intra- and interpersonal social consequences of narcissism: narcissistic admiration and rivalry (Back et al., 2013). The agentic 
dimension of narcissism, narcissistic admiration, entails the assertive features of narcissism, such as charming behavior and grandiose fantasies. The antagonistic dimension of narcissism, narcissistic rivalry, reflects the more malicious features of narcissistic traits, such as hostile behavior and aggression (Back et al., 2013).

\section{Narcissism and Romantic Relationships}

Narcissistic individuals are relatively good at attracting potential partners because they seem-at least at first sight-to be interesting, appealing, and exciting (Dufner et al., 2013). At short-time acquaintance, narcissistic men are evaluated by women as physically attractive, charming, humorous, and confident (Back et al., 2010; Rauthmann \& Kolar, 2013). Whereas at longer acquaintance, narcissistic' selfishness, disagreeableness, and lack of empathy become more visible (Paulhus, 1998). Narcissists perceive themselves as superior and extremely important (Back et al., 2013). This excessive form of self-love might be one of the underlying mechanisms of narcissistic' attractiveness (Campbell, 1999). Specifically, the behaviors that represent admiration (e.g., self-confident appearance and charming attitude) might lead to higher romantic attraction (Wurst et al., 2017). By contrast, the behaviors related to narcissistic rivalry (i.e., defending one's grandiose attitude by devaluing others) predict several relationship dysfunctions (e.g., conflicts, manipulation, and hostility; Campbell et al., 2006; Horan et al., 2015; Wurst et al., 2017). As a consequence, narcissistic admiration is linked to romantic success at attracting potential partners for one-night stands, sexual affairs, and dating (Campbell et al., 2006; Jonason et al., 2009), whereas narcissistic rivalry is related to long-term relationship problems (Wurst et al., 2017).

Holtzman and Strube's (2011) evolutionary theory of narcissism suggests that narcissists' short-term romantic success is partly determined by their physical attractiveness, as this is an important predictor for attracting potential partners. Along with this theory, Morf and Rhodewalt (2001) state that narcissists tend to maintain their grandiose self-views by regulating their behavior (e.g., investing in their appearance) to enhance positive evaluations from others. Consequently, narcissists' attractiveness might result from their self-regulation, 
as they receive positive feedback from others, which in turn, will boost their ego. Other research investigating narcissistic' attractiveness using short self-introductory videoclips of narcissistic men, found that men with high levels of narcissistic admiration were evaluated by women as attractive, whereas no effects for narcissistic rivalry were found (Dufner et al., 2013; Wurst et al., 2017). It might be, however, that the impact of narcissism on romantic attraction is different at short- versus long-time acquaintance. Therefore, we aim to replicate these findings by means of pictures of fictional male characters from television shows that are relatively well-known among young women. In this way, women can evaluate their romantic attraction based on both positive and negative aspects of the characters' personality rather than only the initial charming side at short-time acquaintance. This novel approach allows us to investigate the influence of narcissism on romantic attraction at longer acquaintance (vs. at first sight). We hypothesize that women are more attracted to men who score high on narcissistic admiration compared to men who score low on admiration (H1a). We expect no association between romantic attraction and narcissistic rivalry (H1b).

\section{Individual Differences in Romantic Attraction}

Although narcissistic admiration is known to trigger romantic or sexual interest in others (Dufner et al., 2013), the question of why women are (not) attracted to narcissistic men (i.e., admiration and rivalry) remains unanswered. A possible explanation might be the relatively stable individual differences between women, such as women's personality. Most important social interactions, thoughts, and feelings are influenced by personality traits of both people involved (Back et al., 2011). Therefore, we investigated the relation between women's personality traits and their level of attraction towards narcissistic men. Previous studies suggest that individuals are more attracted to romantic partners who have similar levels of personality traits; the so-called similarity effect or assortative mating phenomenon (Watson et al., 2004). When investigating the impact of narcissism on romantic relationships, prior studies showed that individuals high on narcissism indeed prefer romantic partners who are similar in terms of their narcissistic traits (Grosz et al., 2015; Lyons \& Blanchard, 2016). 
Additionally, narcissistic individuals are more likely to engage in relationships that increase their social status (Grapsas et al., 2020), and are more attracted to potential romantic partners who are highly desirable (i.e., confident, ambitious, and physically attractive; Campbell, 1999). Moreover, prior research suggests that women who score high on the Dark Triad (i.e., narcissism, psychopathy, and Machiavellianism), are more attracted to narcissistic men, compared to low scores on the Dark Triad (Burtaverde, 2021). Therefore, we propose that romantic attraction is predicted by how similar women are to men in narcissism (H2).

Besides differences in narcissism, one of the personality traits that might play an important role in explaining why women are romantically attracted to narcissistic men is thrill-seeking. As described above, individuals with high levels of narcissism need others to satisfy their need for admiration. They aim to be in the center of attention by entertaining others, showing off their talents, and bragging about their outstanding performances (Back et al., 2013). In turn, individuals high on thrill-seeking desire to be entertained by others and tend to be in exciting situations (Andershed et al., 2002). Women high on thrill-seeking generally prefer dominant men with exciting personalities who can easily entertain them (Giebel et al., 2015). Moreover, sensation seekers are more attracted to potential partners with risky personality traits (Henderson et al., 2005). In a similar study on romantic attraction using personality vignettes, Grosz et al. (2015) found that individuals with high levels of sensation-seeking were more attracted to narcissistic admiration and rivalry compared to individuals with low levels of sensation-seeking. Therefore, we expect a positive association between women's thrill-seeking and their attraction to men's narcissistic admiration and rivalry compared to women who score low on thrill-seeking $\left(\mathrm{H}_{3}\right)$.

A related trait that might be an important aspect of why women are attracted to narcissistic men is impulsivity. Being impulsive predicts interest in short-term sexual relationships, such as booty-calls, one-night-stands, and friends-with-benefits (Koladich \& Atkinson, 2016). Narcissists, in turn, report a greater desire for short-term casual sex and claim to have several lifetime sexual partners (Jonason et al., 2009). It might be that women 
who are attracted to narcissistic men are similar in terms of their interests in short-term mating, and therefore, are more attracted to narcissistic men. Indeed, prior literature on narcissism suggests that impulsivity is an important predictor of narcissists' behavior (Vazire \& Funder, 2006). Since narcissists are relatively good in attracting potential partners for sexual short-term relationships (Campbell et al., 2006; Jonason et al., 2009), we hypothesize that women who score high on impulsivity are more attracted to men who score high on narcissistic admiration and rivalry compared to women with low levels of impulsivity $\left(\mathrm{H}_{4}\right)$.

Another possible explanation of why women are attracted to narcissistic men might be women's attachment style. Individual differences in attachment style have been shown to influence romantic relationship formation and dating processes (Poulsen et al., 2013; Schindler et al., 2010). Therefore, we examined whether women's attachment style is associated with their level of attraction towards narcissistic men. Bowlby (1973) defines attachment as an emotional, enduring bond between child and primary caregiver. Based on early experiences, individuals develop an internal working model of the self and others that serves as guidance for how to build intimate relationships during their life. This internal working model is integrated into the individual's personality structure and is based on the history of attachment relationships and the quality of these experiences (Bowlby, 1973). A safe and secure internal working model (i.e., secure attachment) is derived from the maintenance of the bond in which the child is confident in the availability (i.e., accessibility and responsiveness) of the attachment figure when needed (Armsden \& Greenberg, 1987). At any stage of life, individuals are most well-adjusted when they have confidence in the availability of a trusted other. Moreover, individuals who are relatively securely attached, are generally more satisfied with themselves (Armsden \& Greenberg, 1987) and feel comfortable developing intimate relationships with others (Collins, 1996). Nevertheless, individuals can also develop a negative internal working model of the self (i.e., insecure attachment), perceiving oneself as unworthy and unable to be loved (Collins, 1996). Insecure attachment can be divided into two dimensions: anxiety (i.e., fear of being rejected or unloved) and avoidance (i.e., fear of 
dependency or intimacy) (Hazan \& Shaver, 1987). Prior research showed that anxious attachment predicts women's preferences for partners with an abusive personality (i.e., violence, aggression, impulsivity, and jealousy; Zayas \& Shoda, 2007). Moreover, women with trait anxiety prefer dominant romantic partners because they will make them feel safe and protected (Giebel et al., 2015; Snyder et al., 2008). In romantic relationships, narcissistic individuals tend to dominate their partner by perceiving themselves as better than their partner (Campbell \& Foster, 2002; Campbell, Foster, et al., 2002). Given that narcissism is highly related to dominance, aggression, and violence, we expect that women who score high on anxious attachment are more attracted to men who score high on admiration and rivalry compared to women who score low on anxious attachment $\left(\mathrm{H}_{5}\right)$. Despite the large amount of literature on attachment and romantic relationships, little is known about the influence of avoidant attachment on partner preferences for particular personalities or romantic attraction towards narcissism. Therefore, we will explore whether there is an association between women's avoidant attachment style and their level of attraction towards narcissistic men.

A great amount of evidence indicating that narcissists are attractive romantic partners is based on self-reports of narcissists. Yet, these self-report measures are associated with several limitations, especially when investigating narcissism (Dufner et al., 2013). Individuals high in narcissism tend to brag about their performances (Back et al., 2013), claim to easily meet women (Morf \& Rhodewalt, 2001), consider themselves as unrealistically positive (Campbell \& Foster, 2007), and respond defensively when their self-view is threatened (Paulhus \& Vazire, 2007), which might influence the outcome of the study. Dufner et al. (2013) recommend that when judgments of potential romantic partners are of interest, the main source of evidence should be by potential partners themselves. Therefore, we investigated potential partners (i.e., heterosexual women) and asked them to what extent they feel romantically attracted to fictional male characters who scored relatively high or low on narcissism.

\section{The Present Research}


The present research aimed to investigate why women are (not) attracted to narcissistic men. Although narcissism predicts several conflicts and difficulties in romantic relationships, narcissists still manage to be successful in attracting potential romantic partners (Jonason et al., 2009). However, most studies investigating the association between narcissism and romantic attraction are based on personality vignettes (e.g., Rauthmann \& Kolar, 2013) or narcissists' self-report (e.g., Campbell \& Foster, 2002). In contrast to previous research, we conducted a novel experiment using pictures of fictional male characters with relatively high or low levels of narcissism, and we asked heterosexual women how romantically attracted they are to the character. Thereafter, participants were asked to rate the same set of fictional characters on narcissistic admiration and rivalry. A meta-analysis showed that otherratings of personality can be used to accurately and validly measure personality traits (Connelly \& Ones, 2010). More specifically for narcissism, previous research suggests that other-ratings of narcissism incorporate specific trait-relevant information, which might enhance the interpretation of narcissism that would have been unrecognized otherwise (Malesza \& Kaczmarek, 2020). Moreover, we believe that pictures would elicit more arousal and less socially desirable answers (Kensinger \& Schacter, 2006; Krause \& Rucker, 2020) than asking participants if they are attracted to narcissists. Finally, we applied response surface methodology which allowed us to test whether the (mis)match between women's characteristics and men's narcissism is associated with higher levels of romantic attraction visualized in a three-dimensional plot (Barranti et al., 2017). Visualization of the response surface coefficients facilitates understanding of the findings. Moreover, we applied multilevel to response surface analysis (RSA) which enabled us to investigate the impact of narcissism on romantic attraction between and within women. By exploring these associations, we aimed to obtain novel insights into why women are attracted to narcissistic men. Such knowledge is of high practical relevance of relationship formation and partner choice. Identifying women who are attracted to narcissistic men can possibly help to implement and improve prevention or intervention programs related to narcissism in romantic relationships. 


\section{General Method}

Before we performed our main study on romantic attraction (Study 2), we conducted a pilot study to select pictures of fictional characters who score relatively high or low on narcissism (Study 1). We preregistered our picture selection criteria (https://osf.io/5kx7p) and statistical plan (https://osf.io/gez8k) via the Open Science Framework. Since physical appearance is one of the most important predictors for romantic attraction (Holtzman \& Strube, 2011), we aimed to select pictures of men who score approximately equal on their physical appearance. For both studies, ethical approval from the Ethical Review Board of Tilburg University was obtained (Project RP488). Participants were informed about the purpose of the study prior to participation. Informed consent from each participant was acquired and we asked participants if they agreed upon openly sharing the data. The current study is part of a larger project entitled "Individual Differences in Romantic Attraction" of which the research materials are provided through the Open Science Framework (https://osf.io/bmtw5/).

\section{Study 1: Picture Selection}

\section{Method}

Participants and Procedure. Heterosexual women were approached using convenience sampling to rate 83 pictures of fictional male characters in an online experiment in Qualtrics. The pictures were preselected by two independent researchers. Inclusion criteria were that the participants are Dutch-speaking, aged between 16 and 25 years, female, and heterosexual. The sample consists of 122 women $\left(M_{\mathrm{age}}=21.60, S D=2.47\right)$, see Table 1 for detailed information of the demographic variables. The aim of the first study was to select 25 pictures of fictional characters that most adolescents and young adults are familiar with, are considered approximately equally handsome, and score relatively high or low on admiration and rivalry. Therefore, participants were asked whether they were familiar with each of the fictional characters $(1=$ yes; $\mathrm{o}=$ no). On average, participants were familiar with $24.8 \%$ of the fictional characters $(M=20.61, S D=11.29)$. 


\section{Table 1}

Demographic Information of Study 1

\begin{tabular}{lcc}
\hline Characteristic & $n$ & $\%$ \\
\hline Highest educational level & & \\
Primary education & 1 & $0.8 \%$ \\
Pre-secondary vocational education & 1 & $0.8 \%$ \\
Senior general secondary education & 16 & $13.1 \%$ \\
Pre-university education & 21 & $17.2 \%$ \\
Post-secondary vocational education & 24 & $19.7 \%$ \\
Higher professional education & 25 & $20.5 \%$ \\
Bachelor's degree & 21 & $17.2 \%$ \\
Master's degree & 13 & $10.7 \%$ \\
Other & 0 & $0 \%$ \\
Relationship status & & \\
Single & 51 & $41.8 \%$ \\
Relationship a & 71 & $58.2 \%$ \\
Prefer not to say & 0 & $0 \%$ \\
\hline
\end{tabular}

Note. $N=122$.

a Including all types of romantic relationships.

\section{Materials}

Physical Appearance. Physical appearance was measured by asking participants to rate 83 pictures on a scale from $0=u g l y$ to $5=$ neutral to $10=$ handsome. The total score on physical appearance for each character was calculated by the mean ratings of the participants. The average score on physical appearance was $5.18(S D=1.05)$.

Narcissism Picture-Ratings. Participants were asked to rate the same set of fictional characters (whom they were familiar with) on narcissistic admiration and rivalry. Given the large amount of pictures (i.e., 83) and corresponding items from both projects, we selected two items with the highest factor loadings from the short version of the Narcissistic Admiration and Rivalry Questionnaire (NARQ-S; Leckelt et al., 2018) to obtain a global overview of narcissism for each character. In order for the items to be appropriate for pictureratings, we slightly rephrased the sentences. For example: Please indicate how much the following statements apply to [name of character] using a response format ranging from $1=$ not agree at all to 6 = agree completely. "Being a very special person gives him a lot of strength.” (i.e., admiration) and "He wants his rivals to fail." (i.e., rivalry). For each character, 
the total score on admiration or rivalry was calculated by the mean ratings of the participants, with scores ranging from 1 to 6 . The mean score on admiration was $3.92(S D=.62)$ and the mean score on rivalry was $3.52(S D=.68)$.

\section{Results and Discussion}

Based on the results of the first study, we selected 25 pictures of fictional characters that were used in Study 2. The preregistered plan was to remove pictures of fictional characters that 1) $40 \%$ of the participants were not familiar with, and 2) scored below 7 on physical appearance. On average, each fictional character was known by $20.6 \%$ of the participants. Since many characters were not well-known by the participants, and the mean ratings on physical appearance was unexpectedly low $(M=5.18, S D=1.05)$, we had to deviate from our preregistered selection criteria. Accordingly, fictional characters of which more than $80 \%$ of the participants were not familiar with and scored below 5 on physical appearance were eliminated from our selection. Subsequently, we selected characters who scored relatively high and low on admiration and rivalry, resulting in a total of 25 pictures that were used in Study 2. The mean score on physical appearance of the 25 characters was $6.44(S D=1.06)$. Even though we had to deviate from our picture selection, we still selected characters who were rated approximately equal on their physical appearance. For a detailed overview of the descriptive statistics of the characters used in Study 2, see Supplementary materials.

\section{Study 2: Romantic Attraction}

\section{Method}

Participants and Procedure. The sample consists of heterosexual women who were approached using convenience sampling and a platform (Sona) on which first-year undergraduate students from Tilburg University could obtain course credits. Students could obtain one course credit which is equal to one participation hour. Other participants were not rewarded for participation. Similar to the first study, inclusion criteria were that the participants are Dutch-speaking, aged between 16 and 25 years, female, and heterosexual. Demographic information of the participants was obtained, such as age, educational 
background, and relationship status. The questionnaire consisted of two picture-based experiments followed by self-report measures. In the first picture-based experiment, participants were asked to rate 25 pictures selected in Study 1 on how romantically attracted they are to the personality of the fictional character. During the second picture-based experiment, participants were asked to rate the same set of fictional characters (whom they were familiar with) on narcissistic admiration and rivalry.

We excluded participants who did not meet the age range of the study $(n=2)$, who were not familiar with any character $(n=1)$, and who did not rate any character on narcissism $(n=2)$, resulting in a total sample of 195 women $\left(M_{\text {age }}=20.78, S D=2.40\right)$. For a detailed overview of the demographic variables, see Table 2. Since the notoriety of the fictional characters used in Study 1 was unexpectedly low, we incorporated an additional response for participants in which they could specify whether they knew the character a bit for Study 2. Concretely, participants were asked whether they were familiar with the character $(1=y e s ; 2$ $=a$ bit; $3=n o$ ). On average, participants were (a bit) familiar with $59.7 \%$ of the characters.

\section{Table 2}

Demographic Information of Study 2

\begin{tabular}{lcc}
\hline Characteristic & $n$ & $\%$ \\
\hline Highest educational level & & \\
Primary education & 0 & $0 \%$ \\
Pre-secondary vocational education & 6 & $3.1 \%$ \\
Senior general secondary education & 22 & $11.3 \%$ \\
Pre-university education & 79 & $40.5 \%$ \\
Post-secondary vocational education & 22 & $11.3 \%$ \\
Higher professional education & 36 & $18.4 \%$ \\
Bachelor's degree & 14 & $7.2 \%$ \\
Master's degree & 12 & $6.1 \%$ \\
Other & 4 & $2.1 \%$ \\
Relationship status & & \\
Single & 94 & $48.2 \%$ \\
Relationship a & 100 & $51.3 \%$ \\
Prefer not to say & 1 & $0.5 \%$ \\
\hline
\end{tabular}

Note. $N=195$.

a Including all types of romantic relationships.

\section{Materials}


Romantic Attraction. Romantic attraction was assessed using 25 pictures of fictional male characters. In particular, participants were asked to rate the extent to which they feel romantically attracted to personality of the character (whom they were familiar with) on a score ranging from $\mathrm{o}=$ repulsed to $5=$ neutral to $10=$ attracted . For example: "To what extent do you feel romantically attracted to Jordan Belfort?”. It was emphasized to focus on the personality of the fictional character rather than their physical appearance when answering this question.

Narcissism Picture-Ratings. Participants were asked to rate each fictional character (whom they were familiar with) on narcissistic admiration and rivalry using the NARQ-S. The NARQ-S consists of six items, three for each dimension, and one for each facet. Admiration contains the following three facets: strive for uniqueness, charmingness, and grandiosity (e.g., "I deserve to be seen as a great personality.”). Rivalry consists of strive for supremacy, devaluation, and aggressiveness (e.g., "I react annoyed if another person steals the show from me.”). Small changes were made for the items to be suitable for picture-ratings. For example: "He deserves to be seen as a great personality.". For each character, the total score on admiration or rivalry was calculated by the mean ratings of each participant (range: $3^{-18}$ ). Jordan Belfort, for example, scored 12.60 on admiration and 13.34 on rivalry. The Cronbach's alphas at the between-person level measured within the current study were .78 for admiration and .83 for rivalry, indicating an acceptable internal consistency. For a detailed overview of the reliability coefficients and picture-ratings of narcissism for each character, see Supplementary materials.

Narcissism Self-Ratings. Participant's score on narcissism was also assessed using the NARQ-S (Leckelt et al., 2018). For each participant, the total score on admiration or rivalry can range from 3 to 18 . The NARQ-S allowed us to measure admiration and rivalry reliably and validly as two positively related yet distinct dimensions (Back et al., 2013; Leckelt et al., 2018). In particular, NARQ-S provided a reliability score of .84 for admiration and .70 for rivalry in a representative sample (Leckelt et al., 2018). The Cronbach's alphas at the between- 
person level measured within the current sample were .80 for admiration and .71 for rivalry, suggesting an acceptable internal consistency.

Thrill-Seeking and Impulsivity. Thrill-seeking and impulsivity were measured using the Youth Psychopathic Traits Inventory (YPI; Andershed et al., 2002). Both subscales consist of five items. Example questions are: "I like to be where exciting things happen." (i.e., thrill-seeking) and "I consider myself as a pretty impulsive person." (i.e., impulsivity). Participants were asked to rate each statement on a 4-point Likert scale ranging from $1=$ does not apply to 4 = applies very well. For both impulsivity and thrill-seeking, the total score contains the sum of the five items, with scores ranging from 4 to 20. Both subscales of the YPI provided acceptable reliability scores ( $\alpha=.66$ for thrill-seeking and $\alpha=.65$ for impulsivity) measured in the general population (Andershed et al., 2002). In the current study, the internal consistency of the subscales measured at the between-person level ( $\alpha=.75$ for thrill-seeking and $\alpha=.66$ for impulsivity) was considered acceptable.

Adult Attachment. Attachment was measured using the Dutch Revised Adult Attachment Scale (RAAS; Collins, 1996; Van Aken et al., 2017). The RAAS consists of each 6 items on three dimensions (i.e., closeness, dependence, and anxiety) assessing how participants generally feel in important close relationships. With the closeness domain, we assessed the extent to which participants are comfortable with closeness and intimacy (e.g., "I am comfortable developing close relationships with others.”). With the dependency domain, we assessed the extent to which participants feel they can trust and depend on others (e.g., "I know that people will be there when I need them.”). Finally, with the anxiety domain, we assessed the extent to which participants are worried about being rejected or unloved (e.g., "I often worry that other people don't really love me."). Participants were asked to rate each statement on a 5-point Likert scale ranging from $1=$ not at all characteristic of me to $5=$ very characteristic of me. In the current study, we used the anxiety subscale which consists of the sum score of all items on the anxiety domain (range: 5-30). Moreover, we used the avoidant subscale consisting of all items of the dependence domain and the revised items of the 
closeness domain (range: 5-60). All three RAAS subscales showed acceptable reliability scores; Cronbach's alphas were .77 for closeness, .80 for dependency, and .86 for anxiety (Graham \& Unterschute, 2015). In the current study, both domains provided good reliability scores measured at the between-person level ( $\alpha=.85$ for anxiety and $\alpha=.89$ for avoidant).

\section{Statistical Approach}

All statistical analyses were performed using RStudio (Version 1.4.1106). We created a long data format with each fictional character on a separate row, so that each participant could have multiple rows with different characters. In this way, we incorporated the fact that not every participant was familiar with all 25 fictional characters. As recommended by Schönbrodt (2016b), we standardized all variables to the sample mean and standard deviation for an easier interpretation. We used Restricted Maximum Likelihood (REML) to handle missing values.

Multilevel Modelling. As a first step in investigating the association between narcissism and romantic attraction, we used multilevel modelling (MLM) to investigate whether women are more attracted to men scoring high on narcissistic admiration compared to lower levels of admiration (H1). We used lme4 package in RStudio (Version 1.1.26) (Bates et al., 2020). Using MLM, we were able to investigate women's level of romantic attraction towards several fictional characters with relatively high or low levels of narcissism (i.e., the within-person effect; Level-1). We added the (estimated) age of the character as a control variable because it might affect the extent to which participants perceive the character as attractive.

Response Surface Methodology. To examine why women are (not) romantically attracted to narcissists ( $\mathrm{H}_{2}$ to $\mathrm{H}_{5}$ ), we applied multilevel response surface analysis (ML-RSA) using the RSA package in RStudio (Version 0.10.2) (Schönbrodt, 2016a). We based our analyses on the R-code written by Nestler et al. (2019) (for more details, see https://osf.io/jhyuq). RSA conceptually requires two steps: 1) Performing polynomial regression modelling and 2) visualization of the estimated regression equation in a response surface plot to test how the congruence between two predictors relates to romantic attraction 
(Barranti et al., 2017). Again, the age of the character was added as a control variable. We centered the congruence predictors on the grand mean across both variables.

Step 1: Performing Polynomial Regression Modelling. The first step of RSA is the estimation of a multilevel polynomial regression model (Nestler et al., 2019). For all hypotheses, we regressed romantic attraction $(Z)$ on the main effects of the predictors ( $X$ and $Y$ ), their squared terms $\left(X^{2}\right.$ and $\left.Y^{2}\right)$, and the interaction term $(X Y)$. To predict romantic attraction towards character $c$ (Level-1) within individual $i$ (Level-2), the multilevel polynomial regression equation on Level-1 was:

$$
\text { Romantic attraction }_{c i}=b_{0 i}+b_{1 i} X_{c i}+b_{2 i} Y_{c i}+b_{3 i} X_{c i}^{2}+b_{4 i} X_{c i} Y_{c i}+b_{5 i} Y_{c i}^{2}+e_{c i}
$$

The regression coefficients $\left(b_{1}-b_{5}\right)$ were then used to estimate the average response surface coefficients $\left(a_{1}-a_{5}\right)$ across individuals (i.e., Level-2 unit $i$ ). The Level-2 equations for the regression coefficients were:

$$
\begin{aligned}
b_{0 i}=\gamma_{00}+\gamma_{01} \bar{X}_{i}+\gamma_{02} \bar{Y}_{i} & +\gamma_{03} \bar{X}_{i}^{2}+\gamma_{04} \overline{X Y}_{i}+\gamma_{05} \bar{Y}_{i}^{2}+u_{0 i} \\
b_{1 i} & =\gamma_{10}+u_{1 i} \\
b_{2 i} & =\gamma_{20}+u_{2 i} \\
b_{3 i} & =\gamma_{30}+u_{3 i} \\
b_{4 i} & =\gamma_{40}+u_{4 i} \\
b_{5 i} & =\gamma_{50}+u_{5 i}
\end{aligned}
$$

Hypotheses 3 to 5 include measures that were based on different Likert scales and thus were incommensurable. Therefore, we used fit patterns with polynomial regression (Schönbrodt, 2016b). Using fit patterns, we were able to investigate whether the combination of two psychological constructs (i.e., women's attachment and men's narcissism) is related to optimal values on an outcome variable (i.e., romantic attraction). Fit patterns can be defined 
by two basic notions: 1) Each level of $X$ has a matching level of $Y$ which leads to an optimal value of $Z$, and vice versa, and 2) deviations from these optimal combinations lead to a suboptimal value of $Z$, with greater deviations having more influence than smaller deviations (Schönbrodt, 2016b). To test for a weak/strong fit pattern, the following constraints must be fulfilled: For a weak fit pattern, $b_{3} b_{5}>0$, and for a strong fit pattern, $b_{1}=\left(b_{2} b_{4}\right) / 2 b_{5}$ and $b_{4}=$ $2 \sqrt{ }\left(b_{3} b_{5}\right)$ (Schönbrodt, 2016b). A weak fit pattern indicates that for each predictor $X$ there is one optimal value $Y$ which maximizes/minimizes the outcome variable $Z$, and vice versa (Schönbrodt, 2016b). A strong fit pattern indicates that the association between optimal matching values is symmetric.

To test whether adding the second-order terms improved the model fit, we examined whether the hypothesized model (i.e., including a congruence effect) significantly fit better than the linear model (i.e., model with only linear predictors). For the (dis)similarity hypotheses (H2), we compared the linear model with our hypothesized model using the standard Akaike Information Criteria (AIC). For the hypotheses testing fit patterns $\left(\mathrm{H}_{3}-\mathrm{H}_{5}\right)$, we used the corrected Akaike Information Criteria (AICc) to compare model fit (Schönbrodt, 2016b). In general, the model with the smallest AIC(c) can be considered as the best model (Schönbrodt, 2016b). More specifically, if the AIC(c) decreased by more than 2, it indicated an improvement in model fit. Once the best model was selected, the absolute model performance was evaluated using the difference in explained variance of the model $\left(R^{2}\right)$.

Step 2: Visualization of Response Surface Plot. The second step of RSA is the visualization of the estimated polynomial regression coefficients in a three-dimensional response surface plot to interpret the meaning of the effects (Schönbrodt, 2016b). In general, when investigating congruence effects using a three-dimensional response surface plot, the line of congruence (LOC) and the line of incongruence (LOIC) are important features (Nestler et al., 2019).

For the (dis)similarity hypothesis (H2), we looked at the LOC and LOIC. The LOC indicates where values of both predictors perfectly match at all levels of the scale $(X=Y)$ (i.e., 
similarity) (Schönbrodt et al., 2018). In contrast, the LOIC reflects all combinations of the predictors for which $Y=-X$ (i.e., dissimilarity). Support for similarity effects on romantic attraction can be determined by the response surface coefficients $a_{1}-a_{5}$ (Nestler et al., 2019). The $a_{1}$ and $a_{2}$ coefficients determine the shape of the LOC $\left(b_{0}+a_{1} X+a_{2} X^{2}\right)$, whereas the $a_{3}$ and $a_{4}$ coefficients determine the shape of the LOIC $\left(b_{0}+a_{3} X+a_{4} X^{2}\right)$. The $a_{1}$ coefficient $\left(a_{1}=\right.$ $b_{1}+b_{2}$ ) reflects the linear main effect of women's and character's narcissism, whereas the $a_{2}$ coefficient $\left(a_{2}=b_{3}+b_{4}+b_{5}\right)$ reflects curvilinear main and interaction effects of women's and men's narcissism. When the $a_{4}$ coefficient $\left(a_{4}=b_{3}-b_{4}+b_{5}\right)$ is significant, $a_{1}$ and $a_{2}$ indicate whether optimal levels of romantic attraction differ for low versus high levels of narcissism. Besides, the $a_{4}$ coefficient reflects whether there is a curvilinear effect along the LOIC, which suggests an optimal level of romantic attraction. Moreover, if $a_{4}$ is significant, $a_{3}$ reflects at which point of the LOIC this optimal level of romantic attraction is achieved. The $a_{5}$ coefficient $\left(a_{5}=b_{3}-b_{5}\right)$ determines the position of the ridge line of the surface, revealing the optimal combination of women's and men's narcissism on romantic attraction.

The fit pattern hypotheses $\left(\mathrm{H}_{3}-\mathrm{H}_{5}\right)$, based on the full polynomial model, investigates linear main $\left(a_{1}=b_{1}+b_{2}\right)$ and the curvilinear main and interaction $\left(a_{2}=b_{3}+b_{4}+b_{5}\right)$ effects of how the joint impact of two predictors is related to romantic attraction. Since our predictors were incommensurable, the LOC and LOIC were meaningless (Schönbrodt, 2016b). Accordingly, the ridge of a possible fit pattern could shift or rotate away from the LOC. These models allow such a shift to discover the optimal combinations of predictors on romantic attraction, but the shift cannot meaningfully be interpreted. Therefore, we focused on the response surface coefficients $a_{1}-a_{5}$ derived from the regression coefficients $b_{1}-b_{5}$ and used the response surface plot to interpret the effects.

\section{Power Analysis}

As far as we know, there is no appropriate method to calculate the exact power for a given sample size when applying multilevel polynomial regression. Therefore, we followed guidelines from prior studies using response surface methodology. As described by 
Schönbrodt et al. (2018), 200 participants are required to detect an increase in explained variance of $5 \%$ with a statistical power of $90 \%$ and an alpha level of .05, when using non-dyadic response surface methodology. With our sample of 195 participants, we nearly reached 90\% power. Moreover, we focused on improvement of the model fit instead of the separate regression coefficients which increased the power of our study.

\section{Results}

Preliminary Analysis. To investigate whether there were differences in romantic attraction between single women and women who are in a relationship, we applied an independent samples $t$-test. We excluded one participant from this analysis, since this participant preferred not to indicate their relationship status. Consistent with our expectations, there were no significant differences in romantic attraction towards the characters between the groups $(t(191.91)=1.30, p=.195)$. Table 3 shows the descriptive statistics and the Pearson's zero-order correlations of all research predictors and romantic attraction. As can be seen in Table 3, character's score on admiration was positively correlated with romantic attraction $(p<.001)$, whereas character's rivalry was negatively correlated with romantic attraction $(p<.001)$.

\section{Table 3}

Descriptive Statistics and Within-Person Level Pearson's Zero-Order Correlations of all Research Variables

\begin{tabular}{|c|c|c|c|c|c|c|c|c|c|c|}
\hline Measure & $M(S D)$ & 1 & 2 & 3 & 4 & 5 & 6 & 7 & 8 & 9 \\
\hline \multicolumn{11}{|l|}{ Outcome } \\
\hline 1. Attraction & $5.42(1.03)$ & - & & & & & & & & \\
\hline \multicolumn{11}{|l|}{ Picture-Ratings } \\
\hline 2. Admiration & $11.61(1.67)$ & $.23^{* * * *}$ & - & & & & & & & \\
\hline 3. Rivalry & $10.82(1.07)$ & $-.28^{* * *}$ & -.01 & - & & & & & & \\
\hline \multicolumn{11}{|l|}{ Self-Ratings } \\
\hline 4. Admiration & & $.06^{* *}$ & .00 & .00 & - & & & & & \\
\hline 5. Rivalry & $5.68(2.55)$ & .02 & .00 & .02 & $.40^{* * *}$ & - & & & & \\
\hline 6. Thrill-Seeking & $11.20(2.99)$ & $.08^{* * * *}$ & .00 & .02 & $.31^{* * *}$ & $.34^{* * * *}$ & - & & & \\
\hline 7. Impulsivity & $9.70(2.78)$ & $.04^{*}$ & .01 & -.01 & $.25^{* * *}$ & $.34^{* * * *}$ & $.51^{* * *}$ & - & & \\
\hline 8. Anxious & $17.84(5.33)$ & .02 & .01 & .02 & .01 & $.26^{* * *}$ & $.17^{* * * *}$ & $.08^{* * * *}$ & - & \\
\hline 9. Avoidant & $30.49(8.99)$ & $-.04^{*}$ & .02 & .02 & $-.04^{*}$ & $.37^{* * *}$ & $.15^{* * * *}$ & -.03 & $.63^{* * *}$ & - \\
\hline
\end{tabular}

Note. $N=195$.

${ }^{*} p<.05 .{ }^{* *} p<.01 .{ }^{* * *} p<.001$. 
Multilevel Modelling. Multilevel analysis was used to investigate whether women are more romantically attracted to men scoring high on admiration compared to men scoring low on admiration (H1). The results of the multilevel analysis can be found in Table 4. We investigated the influence of narcissism on romantic attraction at two levels: women's romantic attraction towards several fictional characters at the within-person level (Level-1) and the differences between women at the between-person level (Level-2). First, a random intercept model was run to investigate whether there was significant variability in romantic attraction between individuals (see Table 4, Model 1). Additionally, the intraclass correlation (ICC) was estimated as an index of proportion of total variance explained by the within-person level variation in romantic attraction (Level-1). In the random intercept model, the ICC was .11 , indicating that $11 \%$ of the variance in romantic attraction was at the within-person level (Level-1).

Next, fictional character' admiration, rivalry, and age were added as Level-1 predictors (see Table 4, Model 2). As predicted, fictional character's level of admiration was a significant predictor of romantic attraction, such that women were more attracted to men scoring high on admiration compared to men who score low on admiration $(p<.001)$. In contrast, fictional character's level of rivalry was negatively related to women's attraction, such that women were less attracted to men scoring high on rivalry compared to low levels of rivalry $(p<.001)$. Furthermore, there was a significant effect of age on romantic attraction, such that younger men were evaluated as more attractive compared to older men $(p=.005)$. When comparing Model 2 to Model 1 using the deviance statistics, model fit improved, $\chi^{2}(3)=496.64, p<.001$.

Finally, the mean picture-ratings of admiration and rivalry were added as Level-2 predictors (see Table 4, Model 3). The mean picture-ratings of admiration were significant, meaning that women who on average rated the characters higher on admiration were more attracted to the characters than women who on average rated the characters lower on admiration $(p<.001)$. Conversely, we found that women who on average rated the characters higher on rivalry were less attracted to the characters compared to women who scored the 
characters lower on rivalry $(p=.014)$. Adding the Level-2 predictors provided a significantly better fit than the previous model, $\chi^{2}(2)=13.65, p=.001$. Furthermore, the Akaike Information Criterion (AIC) decreased by adding the Level-1 and Level-2 predictors, indicating that Model 3 had the best fit (see Table 4, Model 3).

\section{Table 4}

The Effect of Narcissism on Romantic Attraction

\begin{tabular}{|c|c|c|c|c|c|c|}
\hline & \multicolumn{2}{|c|}{ Model 1} & \multicolumn{2}{|c|}{ Model 2} & \multicolumn{2}{|c|}{ Model 3} \\
\hline & $\begin{array}{l}\text { Estimate } \\
\text { (SE) }\end{array}$ & $t$ & $\begin{array}{l}\text { Estimate } \\
\text { (SE) }\end{array}$ & $t$ & $\begin{array}{l}\text { Estimate } \\
\text { (SE) }\end{array}$ & $t$ \\
\hline Intercept & $5.95(.08)$ & $73.62^{* * * *}$ & $5.94(.08)$ & $71.78^{* * *}$ & $5.95(.08)$ & $74.29^{* * * *}$ \\
\hline Level-1: Character & & & & & & \\
\hline Admiration & & & $.66(.04)$ & $15.13^{* * *}$ & $.66(.04)$ & $15.12^{* * *}$ \\
\hline Rivalry & & & $-.75(.04)$ & $-17.25^{* * *}$ & $-.75(.04)$ & $-17.19^{* * * *}$ \\
\hline Age & & & $-.12(.04)$ & $-2.81^{* * *}$ & $-0.12(.04)$ & $-2.78^{* *}$ \\
\hline Level-2: Women & & & & & & \\
\hline Mean Admiration & & & & & $.31(.09)$ & $3 \cdot 44^{* * * *}$ \\
\hline Mean Rivalry & & & & & $-.21(.09)$ & $-2.48^{*}$ \\
\hline Model fit & & & & & & \\
\hline $\mathrm{AIC}$ & 13861 & & 13384 & & 13380 & \\
\hline$R^{2}$ & .00 & & .14 & & .15 & \\
\hline
\end{tabular}

beta weights. The Akaike Information Criterion (AIC) refers to the model fit. The $R$-squared $\left(R^{2}\right)$ indicates the explained variance in romantic attraction within women. ${ }^{*} p<.05 .{ }^{* *} p<.01 .{ }^{* * *} p<.001$.

Response Surface Methodology. Multilevel RSA was used to examine why women are (not) attracted to narcissistic men. We compared whether each of our hypothesized models, fit the actual data. When focusing on the AIC(c), only the models including character's rivalry provided the best fit (see Table 5). Although the polynomial regression coefficients explained a relatively small proportion of the variance in romantic attraction towards narcissistic rivalry (see Table 5), the improvement in model fit justified further investigation (van Scheppingen et al., 2018). For the models including admiration, the model fit did not decrease by more than two by adding the second-order terms, indicating there was no curvilinear main or interaction effect of the congruence of women's traits and men's admiration on romantic attraction (see Table 5). 


\section{Table 5}

Relative Fit of Multilevel Polynomial Models Predicting Romantic Attraction

\begin{tabular}{lcccc}
\hline & \multicolumn{4}{c}{ Level-1 Predictors } \\
\hline & \multicolumn{2}{c}{ Admiration } & \multicolumn{2}{c}{ Rivalry } \\
\cline { 2 - 5 } Level-2 Predictors & $\Delta$ AIC (c) & $\Delta R^{2}$ & $\Delta$ AIC(c) & $\Delta R^{2}$ \\
\hline Similarity & 1.06 & .005 & -28.32 & .013 \\
Thrill-Seeking & 1.42 & .005 & -43.89 & .018 \\
Impulsivity & 3.39 & .005 & -31.34 & .014 \\
Anxious Attachment & .49 & .005 & -19 & .011 \\
Avoidant Attachment & -1.07 & .007 & -25.81 & .013 \\
\hline
\end{tabular}

Note. The fit of the hypothesized model was compared with the model including only the linear predictors. The difference in (corrected) Akaike Information Criterion ( $\triangle \mathrm{AIC}(\mathrm{c}))$ refers to the relative model fit with negative values larger than -2 indicating an improvement in fit. The difference in $R$-squared $\left(\Delta R^{2}\right)$ indicates the gain in explained variance in romantic attraction within women.

In testing whether the multilevel polynomial regression models satisfied the conditions for a (dis)similarity effect $\left(\mathrm{H}_{2}\right)$ or a fit pattern $\left(\mathrm{H}_{3}-\mathrm{H}_{5}\right)$, we looked at the polynomial regression coefficients (see Table 6) and interpreted the effects by visualization of the findings in the three-dimensional response surface plots (see Figure 1). In Figure 1, the black polygons reflect the complete dataset, without outliers (outer polygon), and the location of the inner 50\% of the data points (inner polygon) (Schönbrodt et al., 2018). The middle of the inner polygon indicates the sample mean. Interpretation of the surface is only allowed in the region in the outer polygon. For the contour plots of the polynomial regression models, see Supplementary materials.

Support for a (dis)similarity effect (H2) can be determined by significance testing of the response surface coefficients (Schönbrodt et al., 2018). The $a_{1}$ and $a_{2}$ coefficients determine the shape of the LOC (i.e., similarity effect) whereas the $a_{3}$ and $a_{4}$ coefficients determine the shape of the LOIC (i.e., dissimilarity effect).

Admiration. Against our expectations, adding the second-order terms to the multilevel linear model including women's and men's admiration did not result in an improvement in model fit (see Table 5). Hence, we looked at the main effects of the linear 
model. There was a significant linear main effect of character's admiration $(t(2751.88)=14.71$, $p<$.001) but no significant main effect of women's admiration on romantic attraction $(t$ $(188.67)=1.744, p=.083)$, such that women were more attracted to men scoring high on admiration (vs. low scores), regardless of women's own score on narcissistic admiration.

Rivalry. The polynomial regression model including the similarity effect of rivalry on romantic attraction provided the best fit (see Table 6). Hence, we focused on the response surface coefficients. The significant $a_{1}$ coefficient $(p<$. .o01) reflects the negative linear main effect of women's and fictional character's rivalry, whereas the significant $a_{2}$ coefficient $(p<$ .014) reflects negative curvilinear main effects of women's and character's rivalry, indicating that romantic attraction was higher when similar levels of rivalry matched at lower levels compared to higher levels, but not at the extreme levels (see Figure 1B). Moreover, because the $a_{4}$ coefficient was significant at $p<.001$, the coefficient $a_{3}$ reflects that the optimal level of romantic attraction was achieved when women's rivalry was higher than character's rivalry compared to when character's rivalry was higher than women's rivalry. The negative quadratic term of character's narcissistic rivalry $\left(b_{3}\right)$ seems to be the main driver of the improvement in model fit when adding the second-order terms. This is also visible in Figure 1B, indicating that similarity effects are rather small, and attractiveness shows the strongest (quadratic) decrease when the character is rated higher on rivalry.

When focusing on the models investigating fit patterns $\left(\mathrm{H}_{3}-\mathrm{H}_{5}\right)$, only one model satisfied the condition of a weak fit pattern, whereas no models met the conditions for a strong fit pattern. A weak fit pattern indicates that for each predictor $X$ there is a single optimal value $Y$ which maximizes/minimizes the outcome variable $\mathrm{Z}$, and vice versa (Schönbrodt, 2016b). The model predicting romantic attraction with the joint impact of narcissistic rivalry and thrill-seeking met the conditions of a weak fit pattern (see Table 6). Any result of the polynomial regression that satisfies this condition can be considered as evidence for the presence of a (weak) fit pattern (Schönbrodt, 2016b). However, interpretation should be done carefully as second-degree polynomial regressions are prone to overfitting. Therefore, we 
focused on significance testing of the response surface coefficients. For the models that did not improve by adding the second-order terms, we focused on the main effects of the linear predictors of romantic attraction.

Thrill-Seeking. The multilevel linear model predicting romantic attraction with admiration and thrill-seeking provided the best fit (see Table 5). Therefore, we focused on significance testing of the linear main effects of women's thrill-seeking and fictional character's admiration on romantic attraction. Our results showed that women were more attracted to fictional characters scoring high on narcissistic admiration $(t(2765.45)=14.68$, $p<$.o01) when women scored high on thrill-seeking compared to low levels of thrill-seeking $(t(176.868)=2.078, p=.039)$.

When looking at the models predicting romantic attraction with thrill-seeking and rivalry, the RSA model provided the best fit (see Table 5). As can be seen in Table 6, the interaction effect of women's thrill-seeking and character's rivalry on romantic attraction $\left(b_{4}\right)$ was significant at $p<.001$, indicating that women who scored high on thrill-seeking were (to a small extent) more attracted to narcissistic men compared to low levels of thrill-seeking. Furthermore, the $a_{1}$ and $a_{4}$ were both significant at $p<.001$, suggesting that the combination of low scores on thrill-seeking and low scores on rivalry predicted higher romantic attraction than high levels of thrill-seeking and rivalry (see Table 6 and Figure 1D). The negative quadratic term of character's narcissistic rivalry $\left(b_{3}\right)$ seems to be the main driver of the improvement in model fit when adding the second-order terms. This is also shown in Figure $1 \mathrm{D}$, indicating that congruence effects are rather small, and attractiveness shows the strongest (quadratic) decrease when the character is rated higher on rivalry. Therefore, we need to be careful when interpreting the results.

Impulsivity. The multilevel linear model predicting romantic attraction towards narcissistic admiration with impulsivity provided the best fit (see Table 5). We found that admiration was a significant predictor of romantic attraction $(t(2731.03)=14.51, p<.001)$, whereas no effects for impulsivity were found $(t(181.78)=1.04, p=.301)$, indicating that 
women were more attracted to fictional male characters scoring high on narcissistic admiration, regardless of women's score on impulsivity.

For rivalry, adding the second-order terms significantly improved the model fit (see Table 5). As can be seen in Table 6 , there was a significant (small) interaction effect $\left(b_{4}\right)$ of women's impulsivity and men's rivalry on romantic attraction $(p<.001)$, indicating that women who scored high on impulsivity were (to a small extent) more attracted to narcissistic men compared to low levels of impulsivity $(p<.001)$. Subsequently, we focused on significance testing of the RSA parameters. The $a_{1}$ and $a_{4}$ were significant at $p<.001$, suggesting that women were more attracted to men when their impulsivity score matched at lower levels of rivalry than higher rivalry (see Table 6 and Figure 1 F). However, the negative quadratic term of character's narcissistic rivalry $\left(b_{3}\right)$ seems to be the main driver of the improvement in model fit when adding the second-order terms, indicating that congruence effects are rather small, and attractiveness shows the strongest (quadratic) decrease when the character is rated higher on rivalry. Hence, we need to be careful when interpreting the results.

Anxious Attachment. The multilevel model predicting romantic attraction with only the linear predictors of narcissistic admiration and anxious attachment provided the best model fit (see Table 5). Hence, we focused on the main effects of the multilevel linear model. Fictional character's level of narcissistic admiration was a significant predictor of romantic attraction, such that characters with higher scores on admiration were rated as more attractive compared to characters with low scores on admiration $(t(2750.64)=14.76, p<.001)$. Anxious attachment was not a significant predictor of romantic attraction $(t(186.63=.93, \mathrm{p}=.356)$, meaning that women were more attracted to fictional characters with high scores on admiration (vs. low) regardless of women's score on anxious attachment.

For narcissistic rivalry, the model predicting romantic attraction with the secondorder terms showed the best fit (see Table 5). Accordingly, we focused on significance testing of the RSA coefficient $a_{1}$ and $a_{4}$ to check whether matches at high values predicted romantic attraction differently than matches at low values (Barranti et al., 2017). The $a_{1}$ and $a_{4}$ were 
both significant at $p<.001$, indicating that the combination of low levels of women's anxious attachment and low levels of character's rivalry predicted higher romantic attraction than high levels of anxious attachment and rivalry (see Table 6 and Figure 1H). Again, the negative quadratic term of character's narcissistic rivalry seems to be the main driver of the improvement in model fit when adding the second-order terms, meaning that character's (un)attractiveness was mainly determined by character's score on narcissistic rivalry.

Avoidant Attachment. The multilevel linear model with narcissistic admiration and avoidant attachment provided the best fit (see Table 5). Therefore, we focused on the main effects of the linear model. Fictional character's level of narcissistic admiration was a significant predictor of romantic attraction, such that characters with high scores on admiration (vs. low scores) were rated as more attractive $(t(2704.15)=14.52, p<.001)$. Avoidant attachment was not a significant predictor of romantic attraction $(t(181.26=-1.54$, $\mathrm{p}=.124$ ), meaning that women were more attracted to fictional characters with high scores on admiration (vs. low) regardless of women's score on avoidant attachment.

For narcissistic rivalry, the RSA model provided the best fit (see Table 5). As can be seen in Table 6, there was a significant (small) interaction effect $\left(b_{4}\right)$ of women's avoidant attachment and men's rivalry on romantic attraction $(p=.006)$, suggesting that women who scored high on avoidant attachment (vs. low scores) were (to a small extent) more attracted to narcissistic men. Moreover, both the $a_{1}$ and $a_{4}$ were significant at $p<.001$, indicating that the combination of low levels of women's avoidant attachment and low levels of character's rivalry predicted higher romantic attraction than high levels of avoidant attachment and rivalry (see Table 6 and Figure $1 J)$. However, the negative quadratic term of character's narcissistic rivalry $\left(b_{3}\right)$ seems to be the main driver of the improvement in model fit when adding the secondorder terms, indicating that congruence effects are rather small, and attractiveness shows the strongest (quadratic) decrease when the character is rated higher on rivalry. Therefore, we need to be careful when interpreting the findings. 


\section{Table 6}

Standardized Multilevel Polynomial Regression Coefficients and the Average Response Surface Parameters Predicting Romantic Attraction

\begin{tabular}{|c|c|c|c|c|c|c|c|c|c|c|}
\hline \multirow{4}{*}{ Level-2 Predictors } & \multicolumn{9}{|c|}{ Level-1 Predictors } & \\
\hline & \multicolumn{5}{|c|}{ Admiration } & \multicolumn{5}{|c|}{ Rivalry } \\
\hline & Admiration & Thrill-Seeking & Impulsivity & $\begin{array}{c}\text { Anxious } \\
\text { Attachment }\end{array}$ & $\begin{array}{c}\text { Avoidant } \\
\text { Attachment }\end{array}$ & Rivalry & Thrill-Seeking & Impulsivity & $\begin{array}{c}\text { Anxious } \\
\text { Attachment }\end{array}$ & $\begin{array}{c}\text { Avoidant } \\
\text { Attachment }\end{array}$ \\
\hline & $b[95 \% \mathrm{CI}]$ & $b[95 \% \mathrm{CI}]$ & $b[95 \% \mathrm{CI}]$ & $b[95 \% \mathrm{CI}]$ & $b[95 \% \mathrm{CI}]$ & $b[95 \% \mathrm{CI}]$ & $b$ [95\% CI] & $b[95 \% \mathrm{CI}]$ & $b[95 \% \mathrm{CI}]$ & $b[95 \% \mathrm{CI}]$ \\
\hline \multicolumn{11}{|l|}{$\begin{array}{l}\text { Polynomial } \\
\text { regression }\end{array}$} \\
\hline $\begin{array}{l}b_{1}(\mathrm{X}) \\
b_{2}(\mathrm{Y})\end{array}$ & $\begin{array}{c}.76^{* * *}[.66, .85] \\
.16[-.01, .32]\end{array}$ & $\begin{array}{c}.75^{* * *}[.65, .85] \\
.16[-.01, .32]\end{array}$ & $\begin{array}{l}.75^{* * *}[.65, .85] \\
.08[-.08, .25]\end{array}$ & $\begin{array}{l}.76^{* * *}[.66, .86] \\
.08[-.08, .24]\end{array}$ & $\begin{array}{c}.76^{* * *}[.66, .84] \\
-.16[-.33 \\
.001]\end{array}$ & $\begin{array}{c}-.74^{* * *}[-.83,-.65] \\
.01[-.20, .23]\end{array}$ & $\begin{array}{c}-.74^{* * *}[-.83,-.65] \\
.17^{*}[.01, .33]\end{array}$ & $\begin{array}{c}-.74^{* * *}[-.83,-.65] \\
.11[-.05, . q a 27]\end{array}$ & $\begin{array}{l}-.74^{* * * *}[-.85,-.67] \\
.10[-.11, .20]\end{array}$ & $\begin{array}{l}-.74^{* * *}[-.83,-.65] \\
-.12[-.29, .04]\end{array}$ \\
\hline $\begin{array}{l}b_{3}\left(\mathrm{X}^{2}\right) \\
b_{4}(\mathrm{XY})\end{array}$ & $\begin{array}{l}.15^{* * *}[.08, .22] \\
.00[-.08, .09]\end{array}$ & $\begin{array}{l}.15^{* * *}[.08, .22] \\
-.04[-.12, .05]\end{array}$ & $\begin{array}{l}.15^{* * *}[.07, .22] \\
-.03[-.12, .06]\end{array}$ & $\begin{array}{l}.16^{* * *}[.08, .23] \\
.02[-.08, .10]\end{array}$ & $\begin{array}{l}.16^{* * *}[.08, .23] \\
-.02[-.11, .07]\end{array}$ & $\begin{array}{c}-.42^{* * *}[-.55,-.29] \\
.10^{*}[.02, .19]\end{array}$ & $\begin{array}{c}-.42^{* * * *}[-.55,-.29] \\
.21^{* * * *}[.12, .29]\end{array}$ & $\begin{array}{c}-.41^{* * * *}[-.54,-.28] \\
.15^{* * * *}[.07, .24]\end{array}$ & $\begin{array}{l}-.40^{* * *}[-.53,-.27] \\
.02[-.01, .18]\end{array}$ & $\begin{array}{c}-.29^{* * *}[-.52,-.26] \\
.12^{* *}[.03, .21]\end{array}$ \\
\hline$b_{5}\left(\mathrm{Y}^{2}\right)$ & $\begin{array}{c}-.06[-.20 \\
.08]\end{array}$ & $.05[-.08, .18]$ & $-.02[-.14, .11]$ & $-.02[-.15, .11]$ & $.09[-.04, .23]$ & $.06[-.07, .19]$ & $.06[-.07, .18]$ & $-.03[-.15, .09]$ & $-.02[-.10, .16]$ & $.09[-.04, .22]$ \\
\hline \multicolumn{11}{|l|}{ Response surface } \\
\hline$a_{1}\left(b_{1}+b_{2}\right)$ & $.91^{* * *}$ & $.91^{* * *}$ & $.83^{* * *}$ & $.84^{* * *}$ & $.60^{* * *}$ & $-.73^{* * *}$ & $-.57^{* * *}$ & $-.63^{* * * *}$ & $-.65^{* * * *}$ & $-.86^{* * *}$ \\
\hline$a_{2}\left(b_{3}+b_{4}+b_{5}\right)$ & .09 & .16 & .10 & .15 & $.23^{*}$ & $-.26^{*}$ & -.15 & $-.28^{* *}$ & $-.41^{* * *}$ & -.18 \\
\hline$a_{3}\left(b_{1}-b_{2}\right)$ & $.60^{* * *}$ & $.6 \mathrm{o}^{* * *}$ & $.66^{* * *}$ & $.68^{* * *}$ & $.92^{* * * *}$ & $-.76^{* * *}$ & $-.91^{* * *}$ & $-.85^{* * * *}$ & $-.84^{* * *}$ & $-.62^{* * * *}$ \\
\hline$a_{4}\left(b_{3}-b_{4}+b_{5}\right)$ & .08 & $.24^{*}$ & .16 & .12 & $.27^{* *}$ & $-.47^{* * *}$ & $-.57^{* * * *}$ & $-.59^{* * *}$ & $-.44^{* * * *}$ & $-.43^{* * *}$ \\
\hline$a_{5}\left(b_{3}-b_{5}\right)$ & $.21^{* *}$ & .10 & $.16^{*}$ & $.18^{*}$ & .06 & $-.48^{* * *}$ & $-.48^{* * *}$ & $-.38^{* * *}$ & $-.38^{* * *}$ & $-.48^{* * * *}$ \\
\hline
\end{tabular}

Note. $\mathrm{CI}$ = Confidence Interval. $\mathrm{X}$ = character's narcissism score. $\mathrm{Y}$ = women's self-report score. All models included the age of the character as a control variable.

${ }^{*} p<.05 .{ }^{* * *} p<.01 .{ }^{* * * *} p<.001$ 


\section{Figure 1}

Three-Dimensional Response Surface Plots Predicting Romantic Attraction

A
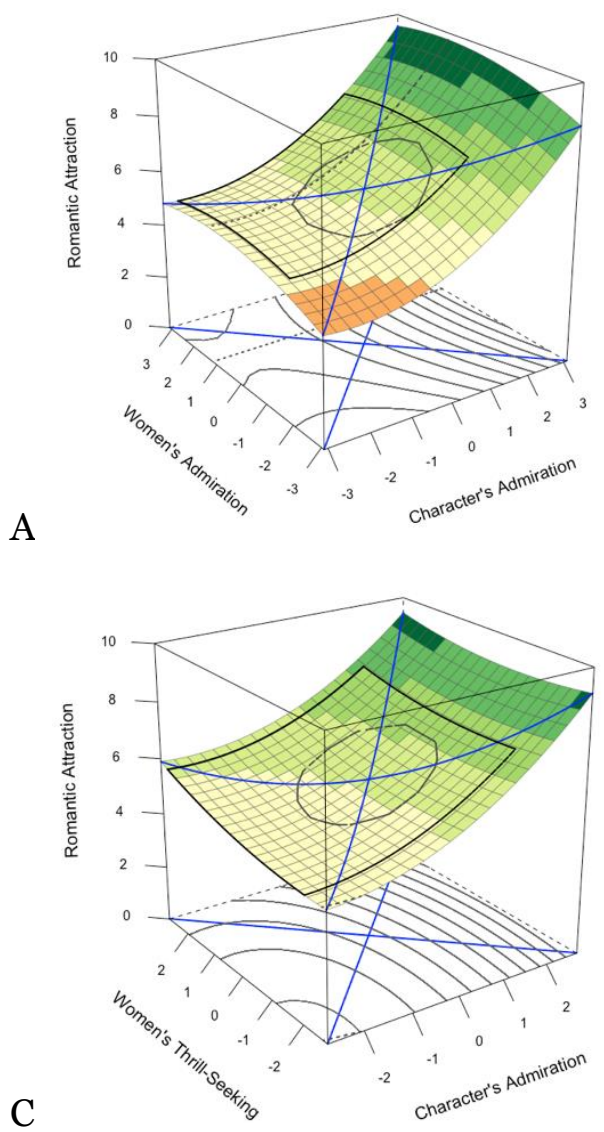

C

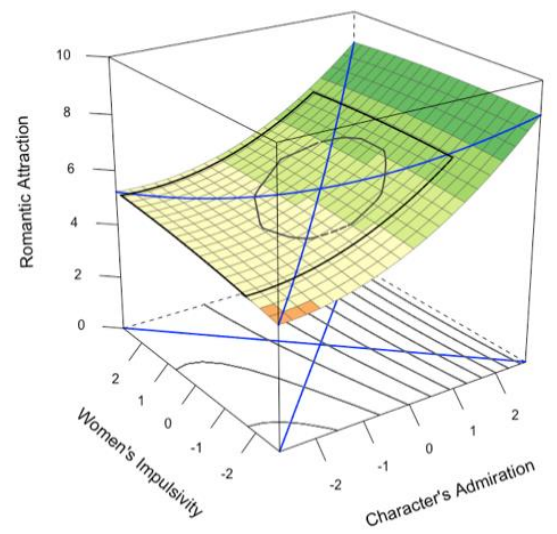

B

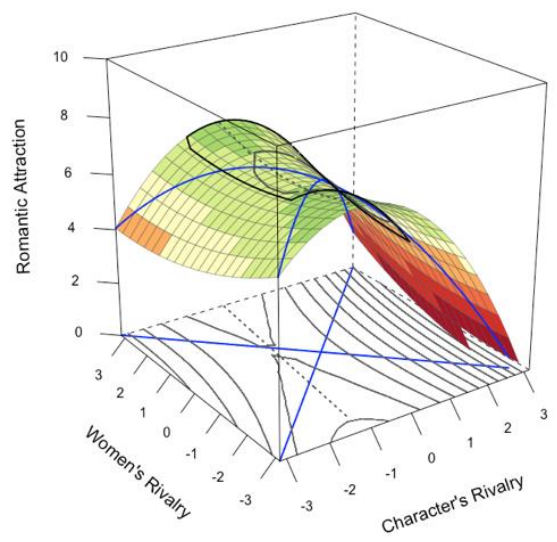

D
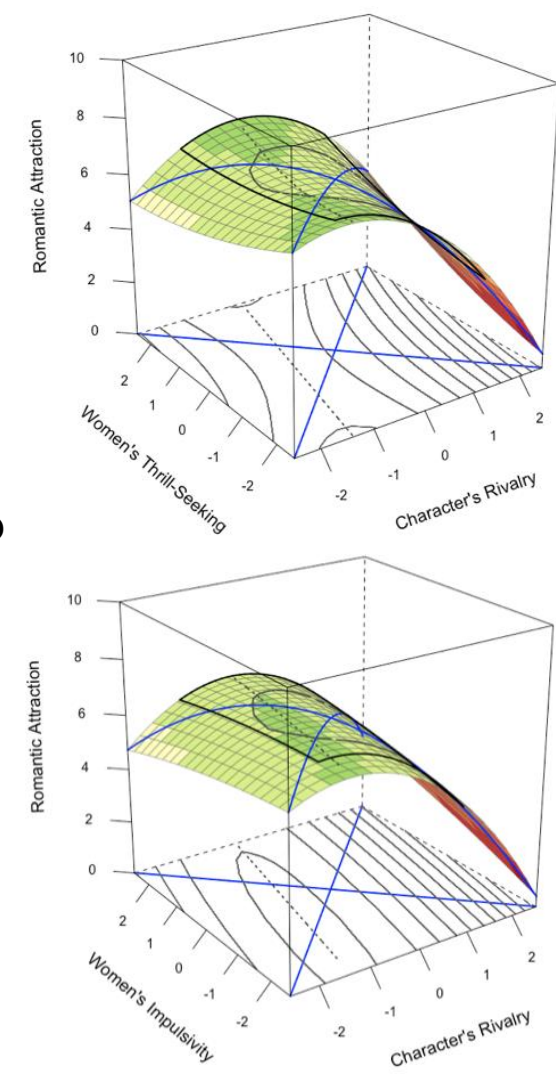

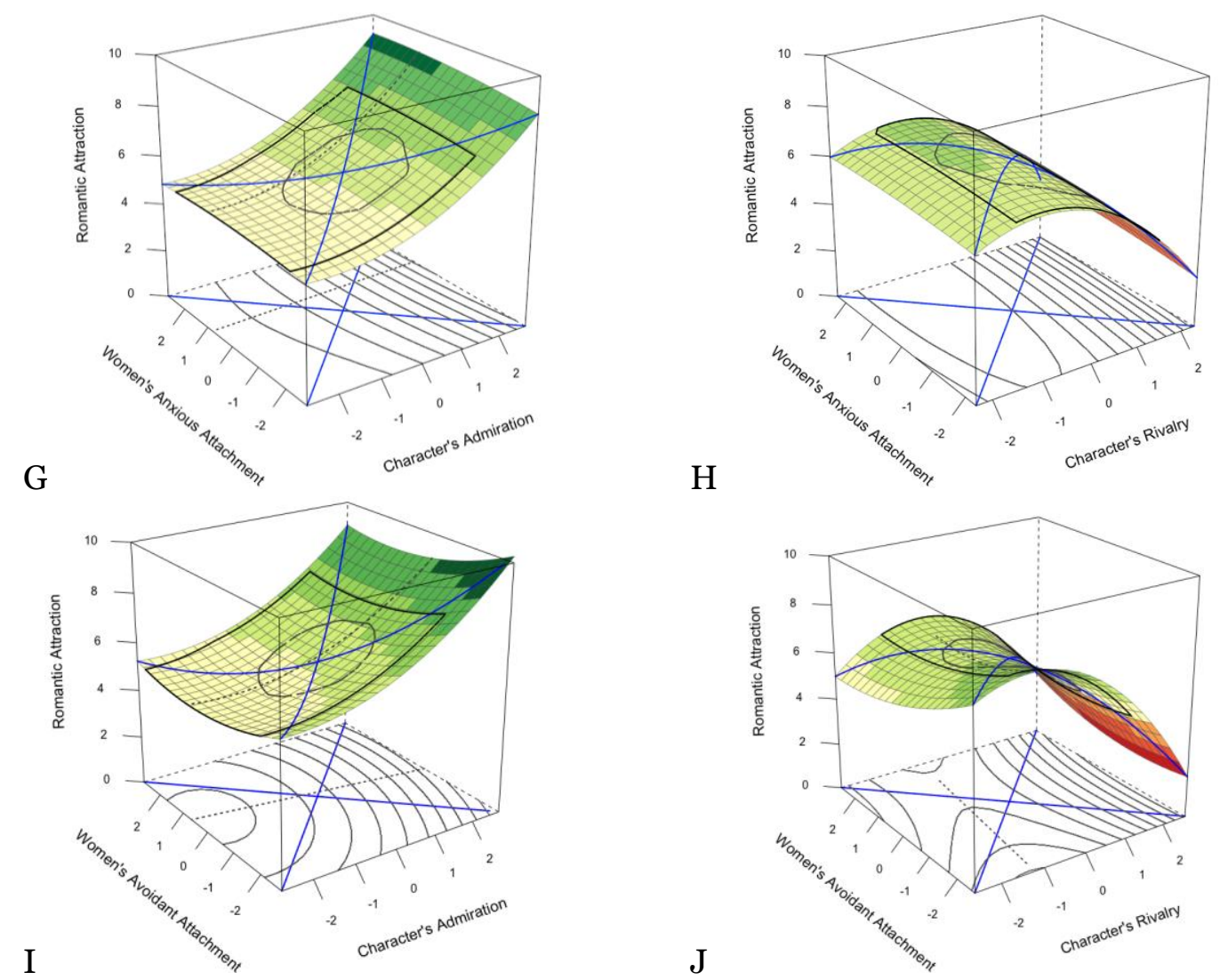

$\mathrm{H}$

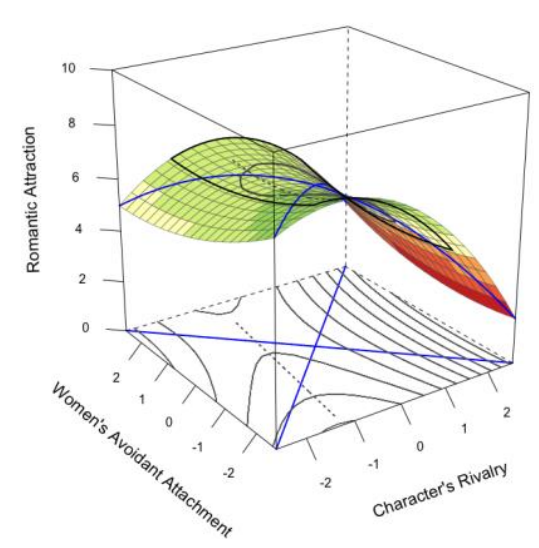

\section{General Discussion}

To the best of our knowledge, the present research was the first to investigate the joint impact of women's characteristics and men's narcissism on romantic attraction using multilevel response surface methodology. This study was furthermore the first that used pictures of fictional male characters to investigate the influence of narcissism on romantic attraction. The results of the present research suggest that distinct men's narcissistic traits play a contradictory role in attracting women. In line with prior research, our study showed that these diverging romantic outcomes might be the result of two related yet distinct dimensions of narcissism that influence romantic relationships differently (Back et al., 2013; Dufner et al., 2013; Wurst et al., 2017). We hypothesized that romantic attraction towards narcissistic men would be determined by men's score on narcissistic admiration but not by men's score on narcissistic rivalry. Our findings indeed showed that narcissists' attractiveness 
might be the result of men's levels of admiration, whereas, in contrast to our expectations, we found that narcissistic rivalry negatively influences romantic attraction.

These findings might be explained by the fact that narcissistic admiration includes the more agentic, charming, and entertaining aspects of narcissism which are associated with higher attractiveness (Dufner et al., 2013). While on the contrary, narcissistic rivalry entails the antagonistic and aggressive facets of narcissism that predict negative long-term relationship outcomes (Back et al., 2013; Wurst et al., 2017). The relatively unattractiveness of narcissistic rivalry might be the result of the tendency of narcissists to use their romantic partner to protect one's positive self-views rather than wanting to develop an intimate longterm relationship (Campbell \& Foster, 2002; Campbell, Rudich, et al., 2002). Another possible explanation of the relatively unattractiveness of narcissistic rivalry might be that we used villainous characters that were extremely violent and evil (e.g., Tom Riddle, the young Voldemort, from Harry Potter) which might negatively influence their attractiveness. Therefore, it might be that other factors related to narcissistic rivalry (e.g., violence) play an important role in the (un)attractiveness of men. Prior research indeed showed that young women prefer to date nice guys over bad guys (Herold \& Milhausen, 1999). Furthermore, when it comes to desirability for a serious romantic relationship, warmth, kindness, and openness were found to be important features of attractive men (Urbaniak \& Kilmann, 2003).

To answer the question of why women are (not) attracted to narcissistic men, we investigated the characteristics of women who are attracted to men scoring high on narcissistic admiration and rivalry. We hypothesized that romantic attraction is predicted by how similar women are to men in narcissism. In contrast to prior research (Grosz et al., 2015; Lyons \& Blanchard, 2016), we found no evidence for a similarity effect of narcissism on romantic attraction. Using fictional characters from television shows with which the participants were familiar, enabled us to investigate the influence of narcissism on romantic attraction at longtime acquaintance. Because participants were familiar with the characters, we believe that they were better able to evaluate the personality of the character as well as their romantic 
attraction towards the personality of the character (vs. at first sight). It might be that similarity in narcissism only plays a role in explaining attraction at a short-time acquaintance in which the more desirable traits of narcissistic men are especially displayed (Back et al., 2010). At long-time acquaintance, on the contrary, narcissistic individuals' malicious traits become more apparent (Paulhus, 1998). Because narcissistic individuals prefer romantic partners who are highly desirable (Campbell, 1999), it might be that narcissistic individuals are less attracted to potential partners who score high on the antagonistic dimension of narcissism (rivalry), compared to low scores on rivalry.

Consistent with our predictions and existing literature (Grosz et al., 2015), our results indicated that women who scored high on thrill-seeking (vs. low levels of thrill-seeking) were more attracted to men with narcissistic admiration, and to a lesser extent to men with narcissistic rivalry. Individuals high on thrill-seeking desire romantic relationships in which they can be easily entertained (Giebel et al., 2015). Since narcissists are good at entertaining others (Back et al., 2013), women might be more attracted to narcissistic men because they have a high need to be entertained (Andershed et al., 2002), and feel more comfortable with such exciting personalities (Giebel et al., 2015). Moreover, individuals who seek out exciting social activities are more attracted to potential partners with risky personality traits (Henderson et al., 2005). Therefore, it might be that women who are attracted to narcissistic men are similar in terms of their interests in dangerous and exciting activities as narcissism is highly related to thrill-seeking and risk-taking behavior (Emmons, 1981; Leder et al., 2020).

Additionally, we hypothesized that women who score high on impulsivity (vs. low scores) are more attracted to men who score high on narcissistic admiration and rivalry. The response surface analysis revealed that women who scored high on impulsivity (vs. low scores on impulsivity) were to a small extent more attracted towards men with high scores on narcissistic rivalry. Women high on impulsivity show a greater interest in short-term sexual relationships (Koladich \& Atkinson, 2016). In turn, narcissistic men are relatively successful in attracting potential partners for casual sex (Campbell et al., 2006; Jonason et al., 2009). It 
might be that women high on impulsivity who are attracted to narcissistic men are similar in their interests in sexual relationships, and therefore, are more attracted to narcissistic men. Against our expectations, we found no association between anxious attachment and romantic attraction to narcissistic men. Anxiously attached individuals are highly committed in their romantic relationships and desire strong connections with their romantic partner (Mikulincer et al., 2003), while narcissistic individuals are less committed in their romantic relationship (Campbell \& Foster, 2002). It might be that anxiously attached women prefer potential partners who are similar in their need for commitment rather than narcissistic partners who do not share the same need for commitment in romantic relationships. For avoidant attachment, there is little research on the relation between attachment and preferences for partner personalities or romantic attraction to narcissistic men, and therefore, we had no prior expectations. The response surface analysis revealed that women who scored high on avoidant attachment (vs. low scores) were to a small extent more attracted to men with narcissistic rivalry. Women high on avoidant attachment tend to avoid intimacy (Collins, 1996). Since narcissism is negatively related to a need for intimacy, it might be that women high on avoidant attachment are more attracted to men with narcissistic rivalry as they both do not feel the need to be intimate. Altogether, the most interesting findings of the present study were the negative curvilinear effects of rivalry and the positive linear main effects of admiration on romantic attraction, indicating that men's high scores on admiration and low scores on rivalry are one of the strongest predictors for narcissistic men's attractiveness.

\section{Strengths, Limitations, and Future Directions}

The greatest strength of our study is that we used a picture-based experiment to assess women's level of romantic attraction towards narcissistic men. We believe that using pictures would elicit more arousal (Kensinger \& Schacter, 2006; Krause \& Rucker, 2020) than asking participants the extent to which they feel romantically attracted towards a description of narcissistic men. Moreover, picture-ratings of narcissism were used to gain a comprehensive 
evaluation of the character's score on narcissistic traits. Prior studies indicated that otherratings of narcissism encompasses relevant information of individuals' personality, which might lead to a more accurate and valid interpretation of narcissism (Malesza \& Kaczmarek, 2020). Another strength of our study is the multilevel structured data that enabled us to investigate the impact of narcissism on romantic relationships between and within women. Women's level of romantic attraction was based on several within-level observations $(N=$ 2908) which increased the power of our study.

While using pictures of fictional male characters is one of the strengths of our study, it is also linked to one of our limitations. It might be that some characters were rated differently on romantic attraction because the pictures differed in terms of their facial expression, appearance, and background. Another limitation of the current study is that most characters (and individuals in daily life) score high on both admiration and rivalry. Therefore, we based our conclusions on specific traits rather than narcissistic individuals in general. One might also argue that the personality of a fictional character is not representative of one's personality in daily life. We however included characters from television shows that were based on true stories (e.g., Jordan Belfort and Ted Bundy) which increased the ecological validity of our study. Nevertheless, future research could try to replicate our findings using a more ecological environment, such as the early phase of a romantic relationship in which romantic attraction towards an actual partner can be investigated. Another limitation is that we limited our study to women's romantic attraction towards narcissistic men while it also could be interesting to investigate romantic attraction towards narcissistic women. For future studies, we recommend exploring more potential predictors of romantic attraction towards narcissism (e.g., Big Five personality traits and self-esteem) to gain a complete insight into who might fall in love with narcissistic men. Future studies could furthermore investigate the influence of ideal partner preferences and dating goals on romantic attraction towards narcissistic men to obtain a more comprehensive understanding of why women might prefer narcissistic partners.

\section{Conclusion}


Taken together, the present study discovered that women differ in terms of their romantic attraction towards narcissistic men. Generally, women are more attracted to men with high levels of narcissistic admiration but are less attracted towards men with high levels of narcissistic rivalry. By investigating why women are attracted to narcissistic men, we found that women might be more attracted to narcissistic men because they have a high need to be entertained and tend to be in exciting yet dangerous situations. Identifying women who are attracted to narcissistic men can help in the treatment or prevention of relationship dysfunctions related to narcissism. Together these findings contribute to the understanding of the contradictory impact of narcissism on romantic relationships. 


\section{References}

American Psychiatric Association. (2013). Diagnostic and statistical manual of mental disorders (5th ed.). American Psychiatric Association. https://doi.org/10.1176/appi.books.9780890425596

Andershed, H. A., Kerr, M., Stattin, H., \& Levander, S. (2002). Psychopathic traits in nonreferred youths: A new assessment tool. In L. S. Eric Blaauw (Ed.), Psychopaths: Current international perspectives (pp. 131-158). Elsevier.

\section{http://urn.kb.se/resolve?urn=urn:nbn:se:oru:diva- 6748}

Armsden, G. C., \& Greenberg, M. T. (1987). The inventory of parent and peer attachment: Individual differences and their relationship to psychological well-being in adolescence. Journal of Youth and Adolescence, 16(5), 427-454.

Back, M. D., Baumert, A., Denissen, J. J. A., Hartung, F. M., Penke, L., Schmukle, S. C., Schönbrodt, F. D., Schröder-Abé, M., Vollmann, M., Wagner, J., \& Wrzus, C. (2011). PERSOC: A unified framework for understanding the dynamic interplay of personality and social relationships. European Journal of Personality, 25(2), 90-107.

\section{https://doi.org/10.1002/per.811}

Back, M. D., Küfner, A. C., Dufner, M., Gerlach, T. M., Rauthmann, J. F., \& Denissen, J. J. (2013). Narcissistic admiration and rivalry: Disentangling the bright and dark sides of narcissism. Journal of Personality and Social Psychology, 105(6), 1013-1037.

\section{https://doi.org/10.1037/aoo34431}

Back, M. D., Schmukle, S. C., \& Egloff, B. (2010). Why are narcissists so charming at first sight? Decoding the narcissism-popularity link at zero acquaintance. Journal of Personality and Social Psychology, 98(1), 132-145.

\section{https://doi.org/10.1037/ao016338}

Barranti, M., Carlson, E. N., \& Côté, S. (2017). How to test questions about similarity in personality and social psychology research: Description and empirical demonstration 
of response surface analysis. Social Psychological and Personality Science, 8(4), 465-475. https://doi.org/10.1177/1948550617698204

Bates, D., Maechles, M., Bolker, B., Walker, S., Christensen, R. H. B., Singmann, H., Dai, B., Scheipl, F., Grothendieck, G., Green, P., Fox, J., Bauer, A., \& Krivitsky, P. N. (2020). lme4: Linear mixed-effects models using 'eigen' and S4 (version 1.1-26). https://cran.r-project.org/web/packages/lme4/index.html

Bowlby, J. (1973). Attachment and loss: Volume II: Separation, anxiety and anger. In Attachment and Loss: Volume II: Separation, Anxiety and Anger (pp. 1-429). London: The Hogarth press and the institute of psycho-analysis.

Burtaverde, V. (2021). Women high on the Dark Triad traits are more attracted to narcissistic males if they are oriented to long term mating and had fewer experiences with unfaithful men. Personality and Individual Differences, 173, 110627.

\section{https://doi.org/10.1016/j.paid.2021.110627}

Campbell, W. K. (1999). Narcissism and romantic attraction. Journal of Personality and Social Psychology, 77(6), 1254-1270. https://doi.org/10.1037/0022-3514.77.6.1254

Campbell, W. K., Brunell, A. B., \& Finkel, E. J. (2006). Narcissism, interpersonal selfregulation, and romantic relationships: An agency model approach. In Self and relationships: Connecting intrapersonal and interpersonal processes (pp. 57-83). Guilford Press.

Campbell, W. K., Bush, C. P., Brunell, A. B., \& Shelton, J. (2005). Understanding the social costs of narcissism: The case of the tragedy of the commons. Personality and Social Psychology Bulletin, 31(10), 1358-1368. https://doi.org/10.1177/0146167205274855

Campbell, W. K., \& Campbell, S. M. (2009). On the self-regulatory dynamics created by the peculiar benefits and costs of narcissism: A contextual reinforcement model and examination of leadership. Self and Identity, 8(2-3), 214-232.

$\underline{\text { https://doi.org/10.1080/15298860802505129 }}$ 
Campbell, W. K., \& Foster, C. A. (2002). Narcissism and commitment in romantic relationships: An investment model analysis. Personality and Social Psychology Bulletin, 28(4), 484-495. https://doi.org/10.1177/0146167202287006

Campbell, W. K., Foster, C. A., \& Finkel, E. J. (2002). Does self-love lead to love for others? A story of narcissistic game playing. Journal of Personality and Social Psychology, 83(2), 340-354. https://doi.org/10.1037//0022-3514.83.2.340

Campbell, W. K., \& Foster, J. D. (2007). The narcissistic self: Background, an extended agency model, and ongoing controversies. In C. Sedikides \& S. J. Spencer (Eds.), The self (pp. 115-138). Psychology Press.

Campbell, W. K., Rudich, E. A., \& Sedikides, C. (2002). Narcissism, self-esteem, and the positivity of self-views: Two portraits of self-love. Personality and Social Psychology Bulletin, 28(3), 358-368. https://doi.org/10.1177/0146167202286007

Collins, N. L. (1996). Working models of attachment: Implications for explanation, emotion, and behavior. Journal of Personality and Social Psychology, 71(4), 810-832.

\section{https://doi.org/10.1037/0022-3514.71.4.810}

Connelly, B. S., \& Ones, D. S. (2010). An other perspective on personality: Meta-analytic integration of observers' accuracy and predictive validity. Psychological Bulletin, 136(6), 1092-1122. https://doi.org/10.1037/a0021212

Dufner, M., Rauthmann, J. F., Czarna, A. Z., \& Denissen, J. J. (2013). Are narcissists sexy? Zeroing in on the effect of narcissism on short-term mate appeal. Personality and Social Psychology Bulletin, 39(7), 870-882.

\section{https://doi.org/10.1177/0146167213483580}

Emmons, R. A. (1981). Relationship between narcissism and sensation seeking. Psychological Reports, 48(1), 247-250. https://doi.org/10.2466/pro.1981.48.1.247

Giebel, G., Moran, J., Schawohl, A., \& Weierstall, R. (2015). The thrill of loving a dominant partner: Relationships between preference for a dominant mate, sensation seeking, 
and trait anxiety. Personal Relationships, 22(2), 275-284.

\section{https://doi.org/10.1111/pere.12079}

Graham, J. M., \& Unterschute, M. S. (2015). A reliability generalization meta-analysis of selfreport measures of adult attachment. Journal of Personality Assessment, 97(1), 3141. https://doi.org/10.1080/00223891.2014.927768

Grapsas, S., Brummelman, E., Back, M. D., \& Denissen, J. J. (2020). The "why" and "how" of narcissism: A process model of narcissistic status pursuit. Perspectives on Psychological Science, 15(1), 150-172. https://doi.org/10.1177/1745691619873350

Grosz, M. P., Dufner, M., Back, M. D., \& Denissen, J. J. A. (2015). Who is open to a narcissistic romantic partner? The roles of sensation seeking, trait anxiety, and similarity. Journal of Research in Personality, 58, 84-95.

\section{https://doi.org/10.1016/j.jrp.2015.05.007}

Hazan, C., \& Shaver, P. (1987). Romantic love conceptualized as an attachment process. Journal of Personality and Social Psychology, 52(3), 511-524. https://doi.org/10.1037/0022-3514.52.3.511

Henderson, V. R., Hennessy, M., Barrett, D. W., Curtis, B., McCoy-Roth, M., Trentacoste, N., \& Fishbein, M. (2005). When risky is attractive: Sensation seeking and romantic partner selection. Personality and Individual Differences, 38(2), 311-325. https://doi.org/10.1016/j.paid.2004.04.010

Herold, E. S., \& Milhausen, R. R. (1999). Dating preferences of university women: An analysis of the nice guy stereotype. Journal of Sex \& Marital Therapy, 25(4), 333343. https://doi.org/10.1080/00926239908404010

Holtzman, N. S., \& Strube, M. J. (2011). The intertwined evolution of narcissism and shortterm mating. In The handbook of narcissism and narcissistic personality disorder (pp. 210-220). https://doi.org/10.1002/9781118093108.ch19

Horan, S. M., Guinn, T. D., \& Banghart, S. (2015). Understanding relationships among the Dark Triad personality profile and romantic partners' conflict communication. 
Communication Quarterly, 63(2), 156-170.

https://doi.org/10.1080/01463373.2015.1012220

Jonason, P. K., Li, N. P., Webster, G. D., \& Schmitt, D. P. (2009). The Dark Triad:

Facilitating a short-term mating strategy in men. European Journal of Personality, 23(1), 5-18. https://doi.org/10.1002/per.698

Kensinger, E. A., \& Schacter, D. L. (2006). Processing emotional pictures and words: Effects of valence and arousal. Cognitive, Affective, \& Behavioral Neuroscience, 6(2), 110126. https://doi.org/10.3758/CABN.6.2.110

Koladich, S. J., \& Atkinson, B. E. (2016). The dark triad and relationship preferences: A replication and extension. Personality and Individual Differences, 94, 253-255. https://doi.org/10.1016/j.paid.2016.01.023

Krause, R. J., \& Rucker, D. D. (2020). Can bad be good? The attraction of a darker self. Psychological Science, 31(5), 518-530. https://doi.org/10.1177/0956797620909742

Leckelt, M., Wetzel, E., Gerlach, T. M., Ackerman, R. A., Miller, J. D., Chopik, W. J., Penke, L., Geukes, K., Küfner, A. C. P., Hutteman, R., Richter, D., Renner, K.-H., Allroggen, M., Brecheen, C., Campbell, W. K., Grossmann, I., \& Back, M. D. (2018). Validation of the Narcissistic Admiration and Rivalry Questionnaire Short Scale (NARQ-S) in convenience and representative samples. Psychological Assessment, 30(1), 86-96. https://doi.org/10.1037/pasooo0433

Leder, J., Foster, J. D., \& Schütz, A. (2020). Willing to do what others won't: Narcissism, risk-taking, and social approval. Personality and Individual Differences, 153, 109672. https://doi.org/10.1016/j.paid.2019.109672

Lyons, M., \& Blanchard, A. (2016). "I could see, in the depth of his eyes, my own beauty reflected": Women's assortative preference for narcissistic, but not for Machiavellian or psychopathic male faces. Personality and Individual Differences, 97, 40-44. https://doi.org/10.1016/j.paid.2016.03.025 
Malesza, M., \& Kaczmarek, M. C. (2020). The convergent validity between self- and peerratings of the Dark Triad personality. Current Psychology, 39(6), 2166-2173. https://doi.org/10.1007/s12144-018-9906-7

Mikulincer, M., Shaver, P. R., \& Pereg, D. (2003). Attachment Theory and Affect Regulation: The Dynamics, Development, and Cognitive Consequences of Attachment-Related Strategies. Motivation and Emotion, 27(2), 77-102.

https://doi.org/10.1023/A:1024515.519160

Miller, J. D., Gentile, B., Wilson, L., \& Campbell, W. K. (2012). Grandiose and vulnerable narcissism and the DSM-5 Pathological Personality Trait Model. Journal of Personality Assessment, 95. https://doi.org/10.1080/00223891.2012.685907

Miller, J. D., Hoffman, B. J., Gaughan, E. T., Gentile, B., Maples, J., \& Keith Campbell, W. (2011). Grandiose and vulnerable narcissism: A nomological network analysis. Journal of Personality, 79(5), 1013-1042. https://doi.org/10.1111/j.14676494.2010.00711.X

Morf, C. C., \& Rhodewalt, F. (2001). Unraveling the paradoxes of narcissism: A dynamic selfregulatory processing model. Psychological Inquiry, 12(4), 177-196. https://doi.org/10.1207/S15327965PLI1204 1

Nestler, S., Humberg, S., \& Schönbrodt, F. D. (2019). Response surface analysis with multilevel data: Illustration for the case of congruence hypotheses. Psychological Methods, 24(3), 291-308. https://doi.org/10.1037/metooo0199

Paulhus, D. L. (1998). Interpersonal and intrapsychic adaptiveness of trait selfenhancement: A mixed blessing? Journal of Personality and Social Psychology, 74(5), 1197-1208. https://doi.org/10.1037/0022-3514.74-5.1197

Paulhus, D. L., \& Vazire, S. (2007). The self-report method. In R. W. Robins, R. C. Fraley, \& R. F. Krueger (Eds.), Handbook of research methods in personality psychology (pp. 224-239). Guilford. 
Poulsen, F. O., Holman, T. B., Busby, D. M., \& Carroll, J. S. (2013). Physical attraction, attachment styles, and dating development. Journal of Social and Personal Relationships, 3O(3), 301-319. https://doi.org/10.1177/0265407512456673

Rauthmann, J. F., \& Kolar, G. P. (2013). The perceived attractiveness and traits of the Dark Triad: Narcissists are perceived as hot, Machiavellians and psychopaths not. Personality and Individual Differences, 54(5), 582-586.

\section{https://doi.org/10.1016/j.paid.2012.11.005}

Schindler, I., Fagundes, C. P., \& Murdock, K. W. (2010). Predictors of romantic relationship formation: Attachment style, prior relationships, and dating goals. Personal Relationships, 17(1), 97-105. https://doi.org/10.1111/j.1475-6811.2010.01255.X

Schönbrodt, F. D. (2016a). RSA: Response surface analysis (version o.1O.2). https://cran.r-project.org/web/packages/RSA/index.html

Schönbrodt, F. D. (2016b). Testing fit patterns with polynomial regression models. https://osf.io/ndggf/

Schönbrodt, F. D., Humberg, S., \& Nestler, S. (2018). Testing similarity effects with dyadic response surface analysis. European Journal of Personality, 32(6), 627-641.

\section{https://doi.org/10.1002/per.2169}

Snyder, J. K., Kirkpatrick, L. A., \& Clark Barrett, H. (2008). The dominance dilemma: Do women really prefer dominant mates? Personal Relationships, 15(4), 425-444. https://doi.org/10.1111/j.1475-6811.2008.00208.x

Urbaniak, G. C., \& Kilmann, P. R. (2003). Physical attractiveness and the "Nice Guy Paradox": Do nice guys really finish last? Sex Roles, 49(9), 413-426. https://doi.org/10.1023/A:1025894203368

Van Aken, B., Bussel, E., \& Wierdsma, A. I. (2017). Nederlandse versie van de Revised Adult Atttachment Scale. https://doi.org/10.13140/RG.2.2.27351.68004

van Scheppingen, M. A., Chopik, W. J., Bleidorn, W., \& Denissen, J. J. A. (2018). Longitudinal actor, partner, and similarity effects of personality on well-being. 
Journal of Personality and Social Psychology, 117(4), e51-e70.

https://doi.org/10.1037/psppooo0211

Vazire, S., \& Funder, D. C. (2006). Impulsivity and the self-defeating behavior of narcissists. Personality and Social Psychology Review, 10(2), 154-165.

https://doi.org/10.1207/s15327957pspr1002 4

Watson, D., Klohnen, E. C., Casillas, A., Nus Simms, E., Haig, J., \& Berry, D. S. (2004). Match makers and deal breakers: Analyses of assortative mating in newlywed couples. Journal of Personality, 72(5), 1029-1068.

https://doi.org/https://doi.org/10.1111/j.0022-3506.2004.00289.x

Wurst, S. N., Gerlach, T. M., Dufner, M., Rauthmann, J. F., Grosz, M. P., Küfner, A. C., Denissen, J. J., \& Back, M. D. (2017). Narcissism and romantic relationships: The differential impact of narcissistic admiration and rivalry. Journal of Personality and Social Psychology, 112(2), 280-306. https://doi.org/10.1037/psppoo00113

Zayas, V., \& Shoda, Y. (2007). Predicting preferences for dating partners from past experiences of psychological abuse: Identifying the psychological ingredients of situations. Personality and Social Psychology Bulletin, 33(1), 123-138.

https://doi.org/10.1177/0146167206293493 


\section{Supplementary Materials}

\section{Table S1}

Descriptive Statistics of the Fictional Characters in Study 1

\begin{tabular}{|c|c|c|c|c|c|c|c|c|}
\hline ID & Actor & Character & Television Show & Age & $\begin{array}{c}\text { Physical } \\
\text { Appearance }\end{array}$ & Admiration & Rivalry & Unknown \\
\hline Q23 & Orlando Bloom & Will Turner & Pirates of the Caribbean & 21 & 6.77 & 3.69 & 3.15 & $50 \%$ \\
\hline Q8 & Penn Badgley & Joe Goldberg & You & 30 & 6.48 & 4.11 & 5.22 & $38.52 \%$ \\
\hline Q25 & Patrick Adams & Mike Ross & Suits & 30 & 5.29 & 4.18 & 3.55 & $63.11 \%$ \\
\hline Q6 & Zac Afron & Ted Bundy & Extremely Wicked, Shockingly Evil and Vile & 27 & 6.17 & 4.62 & 5.49 & $54.10 \%$ \\
\hline Q35 & Regé-Jean Page & Simon Basset & Bridgerton & 29 & $7 \cdot 30$ & 3.85 & 2.73 & $57 \cdot 38 \%$ \\
\hline Q69 & Chace Crawford & Nate Archibald & Gossip Girl & 22 & 6.30 & 3.0 & 2.44 & $50 \%$ \\
\hline Q82 & Chris Hemsworth & Thor & Thor & 25 & 6.80 & 4.97 & 4.13 & $63.11 \%$ \\
\hline Q3 & Robert Pattinson & Cedric Diggory & Harry Potter and the Goblet of Fire & 17 & 5.90 & 3.56 & 1.95 & $53.28 \%$ \\
\hline Q49 & Ian Somerhalder & Damon Salvatore & Vampire Diaries & 25 & 6.67 & 4.46 & 4.45 & $60.66 \%$ \\
\hline Q51 & Leonardo DiCaprio & Jordan Belfort & The Wolf of Wall Street & 30 & 5.75 & 4.61 & 5.18 & $63.93 \%$ \\
\hline Q17 & Eddie Redmayne & Newt Scamander & Fantastic Beasts and Where to Find Them & 30 & 5.07 & 4.18 & 1.84 & $59.84 \%$ \\
\hline Q10 & Gabriel Macht & Harvey Specter & Suits & 41 & 6.52 & 4.54 & 5.05 & $64.75 \%$ \\
\hline Q46 & Patrick Dempsey & Derek Shepherd & Grey's Anatomy & 38 & 6.49 & 4.47 & 2.36 & $70.49 \%$ \\
\hline Q12 & Michele Morrone & Don Massimo & 365 Days & 29 & 6.8 & 3.63 & 4.84 & $64.75 \%$ \\
\hline Q59 & Tom Ellis & Lucifer & Lucifer & 37 & 6.11 & 5.21 & 5.0 & $72.13 \%$ \\
\hline Q60 & Henry Cavill & Superman & Man of Steel & 27 & 6.08 & 5.13 & 3.91 & $79.51 \%$ \\
\hline Q19 & Christian Coulson & Tom Riddle & Harry Potter and the Chamber of Secrets & 16 & 6.27 & 4.8 & 5.6 & $59.02 \%$ \\
\hline Q2 & Jamie Dornan & Christian Grey & Fifty Shades of Grey & 27 & $7 \cdot 54$ & 3.64 & $3 \cdot 56$ & $40.16 \%$ \\
\hline Q7 & Channing Tatum & Magic Mike & Magic Mike & 30 & 7.13 & 3.81 & 2.42 & $45.08 \%$ \\
\hline Q70 & Zac Afron & Philip Carlyle & The Greatest Showman & 29 & 7.67 & 3.94 & 2.58 & $60.66 \%$ \\
\hline Q61 & Bradley Cooper & Phil Wenneck & Hangover & 34 & 6.06 & $3 \cdot 34$ & 2.48 & $63.93 \%$ \\
\hline Q41 & Chad Murray & Edgar Evernever & Riverdale & 37 & 5.64 & 4.74 & 4.97 & $72.13 \%$ \\
\hline Q5 & Leonardo DiCaprio & Jack Dawson & Titanic & 20 & 8.27 & 3.89 & 1.89 & $19.67 \%$ \\
\hline Q18 & Ed Westwick & Chuck Bass & Gossip Girl & 22 & 6.01 & 4.07 & 4.78 & $43.44 \%$ \\
\hline Q30 & Justin Bartha & Doug Billings & Hangover & 30 & 5.82 & 2.47 & 1.64 & $70.49 \%$ \\
\hline
\end{tabular}

Note. $N=122$. Participants were on average 21.60 years old $(S D=2.47)$. The scores on physical appearance, admiration, and rivalry were based on the mean

ratings of the participants. Unknown refers to the percentage of the participants that were not familiar with the character. 


\section{Table S2}

Descriptive Statistics of the Fictional Characters in Study 2

\begin{tabular}{|c|c|c|c|c|c|c|c|c|c|c|}
\hline ID & Actor & Character & Television Show & Age & $\begin{array}{l}\text { Romantic } \\
\text { Attraction }\end{array}$ & Admiration & $\alpha$ & Rivalry & $\alpha$ & $n$ \\
\hline A1 & Orlando Bloom & Will Turner & Pirates of the Caribbean & 21 & 6.83 & 12.13 & .63 & 8.51 & .50 & 119 \\
\hline A2 & Penn Badgley & Joe Goldberg & You & 30 & $3 \cdot 30$ & 10.80 & .64 & 14.06 & .67 & 147 \\
\hline A3 & Patrick Adams & Mike Ross & Suits & 30 & 5.98 & 12.39 & .74 & 9.26 & .56 & 89 \\
\hline A4 & Zac Afron & Ted Bundy & Extremely Wicked, Shockingly Evil and Vile & 27 & $3 \cdot 34$ & 11.15 & .67 & $13 \cdot 31$ & .77 & 106 \\
\hline A5 & Regé-Jean Page & Simon Basset & Bridgerton & 29 & 6.94 & 11.93 & .77 & 8.31 & .78 & 114 \\
\hline A6 & Chace Crawford & Nate Archibald & Gossip Girl & 22 & 7.06 & 10.22 & .67 & 7.28 & .81 & 123 \\
\hline A7 & Chris Hemsworth & Thor & Thor & 25 & 6.41 & 14.15 & .84 & 10.28 & .57 & 97 \\
\hline A8 & Robert Pattinson & Cedric Diggory & Harry Potter and the Goblet of Fire & 17 & 5.67 & 10.77 & .81 & 8.09 & .72 & 127 \\
\hline A9 & Ian Somerhalder & Damon Salvatore & Vampire Diaries & 25 & 7.47 & 13.27 & .78 & 13.00 & .75 & 113 \\
\hline A10 & Leonardo DiCaprio & Jordan Belfort & The Wolf of Wall Street & 30 & 4.72 & 12.60 & .68 & $13 \cdot 34$ & .71 & 125 \\
\hline A11 & Eddie Redmayne & Newt Scamander & Fantastic Beasts & 30 & 5.67 & 13.48 & .78 & 6.02 & .45 & 89 \\
\hline A12 & Gabriel Macht & Harvey Specter & Suits & 41 & 6.71 & 13.07 & .83 & 12.80 & .60 & 97 \\
\hline $\mathrm{A} 13$ & Patrick Dempsey & Derek Shepherd & Grey's Anatomy & 38 & 7.60 & $13 \cdot 77$ & .84 & 6.40 & .73 & 111 \\
\hline $\mathrm{A} 14$ & Michele Morrone & Don Massimo & 365 Days & 29 & 5.85 & 10.92 & .81 & 12.62 & .69 & 111 \\
\hline A15 & Tom Ellis & Lucifer & Lucifer & 37 & 6.32 & $14 \cdot 32$ & .74 & 14.02 & .60 & 89 \\
\hline A16 & Henry Cavill & Superman & Man of Steel & 27 & 5.70 & 14.41 & .81 & 8.65 & .47 & 78 \\
\hline A17 & Christian Coulson & Tom Riddle & Harry Potter and the Chamber of Secret & 16 & 3.98 & 11.87 & .73 & $14 \cdot 38$ & .74 & 108 \\
\hline A18 & Jamie Dornan & Christian Grey & Fifty Shades of Grey & 27 & 6.10 & 11.67 & .77 & 11.30 & .73 & 158 \\
\hline A19 & Channing Tatum & Magic Mike & Magic Mike & 30 & 6.43 & 12.41 & .77 & 8.83 & .70 & 148 \\
\hline A2O & Zac Afron & Philip Carlyle & The Greatest Showman & 29 & 7.12 & 12.47 & .80 & $7 \cdot 77$ & .65 & 104 \\
\hline A21 & Bradley Cooper & Phil Wenneck & Hangover & 34 & $5 \cdot 57$ & 10.20 & .74 & 8.33 & .76 & 109 \\
\hline A22 & Chad Murray & Edgar Evernever & Riverdale & 37 & 2.49 & 9.95 & .58 & 13.44 & .82 & 68 \\
\hline A23 & Leonardo DiCaprio & Jack Dawson & Titanic & 20 & 7.75 & 13.26 & .73 & 6.38 & .74 & 123 \\
\hline A24 & Ed Westwick & Chuck Bass & Gossip Girl & 22 & 6.48 & 12.33 & .77 & 13.03 & .77 & 122 \\
\hline A25 & Justin Bartha & Doug Billings & Hangover & 30 & 5.40 & 8.37 & .77 & 6.00 & .89 & 85 \\
\hline
\end{tabular}

Note. $N=195$. Participants were on average 20.78 years old $(S D=2.40)$. The scores on admiration, rivalry, and romantic attraction were based on the mean

ratings of the participants. 


\section{Figure S1}

Contour Response Surface Plots Predicting Romantic Attraction

A

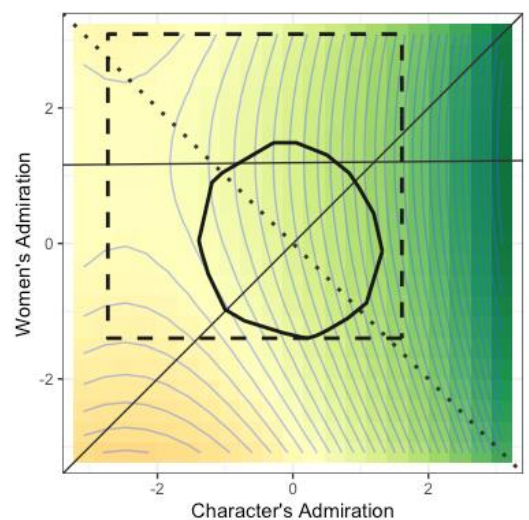

$\mathrm{C}$

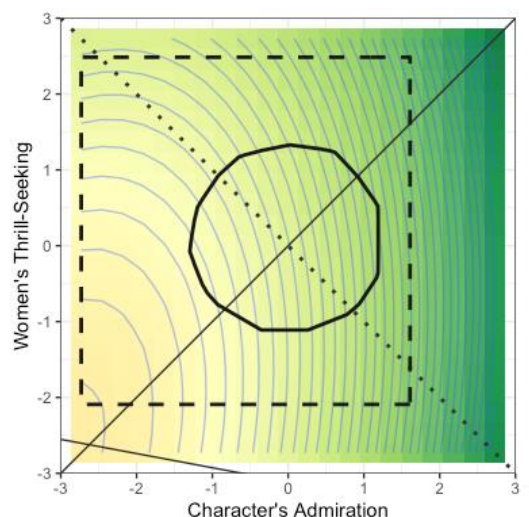

$\mathrm{E}$
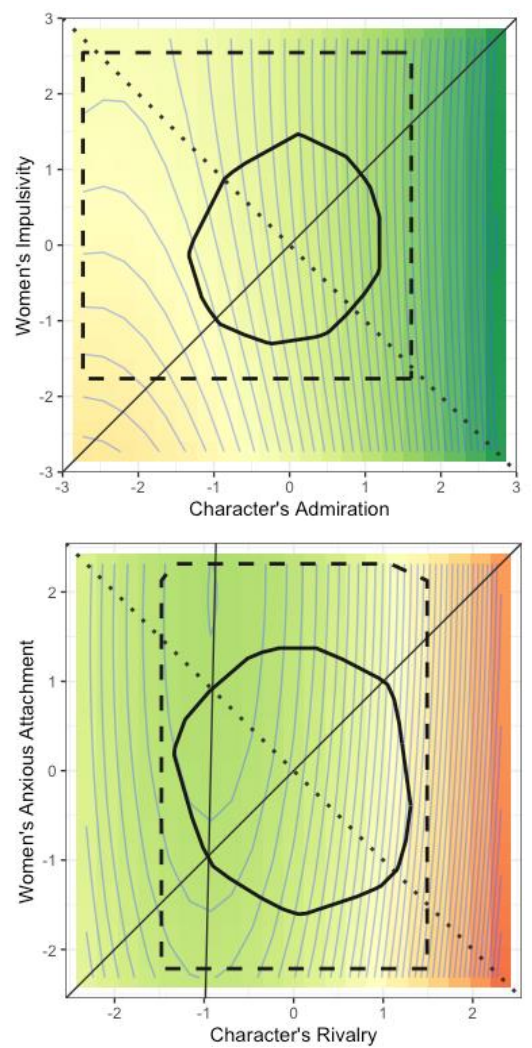

B

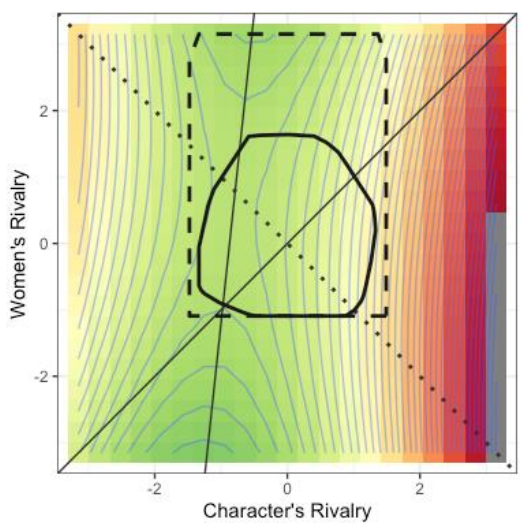

$\mathrm{D}$
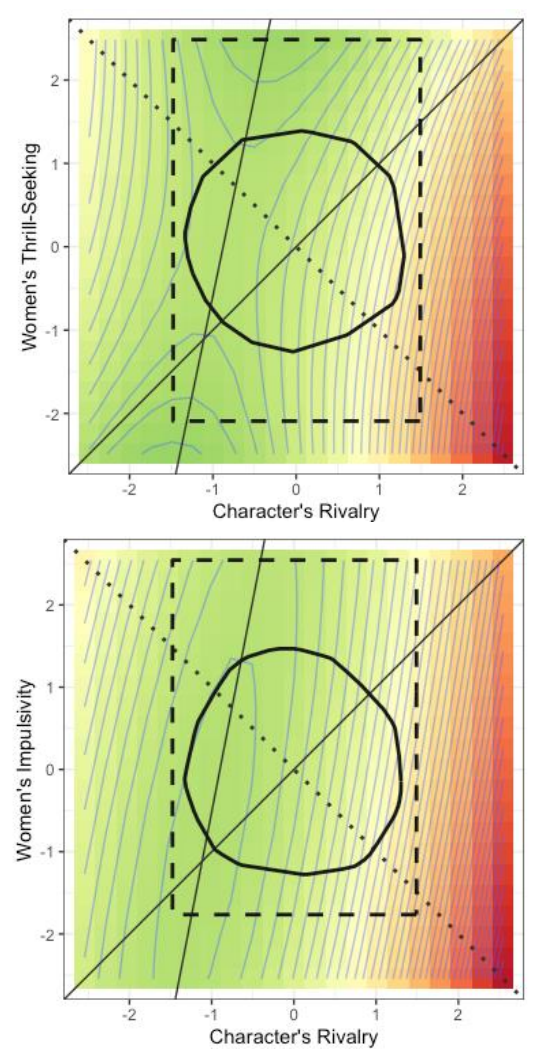

$\mathrm{F}$

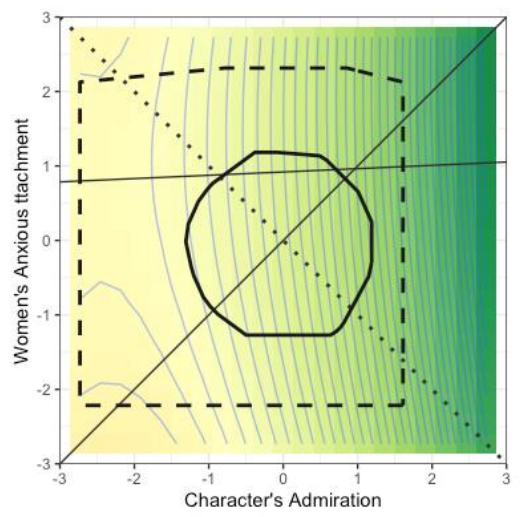

$\mathrm{H}$ 


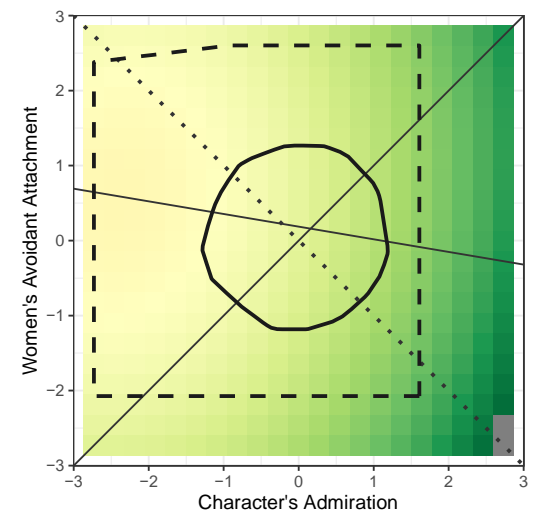

I

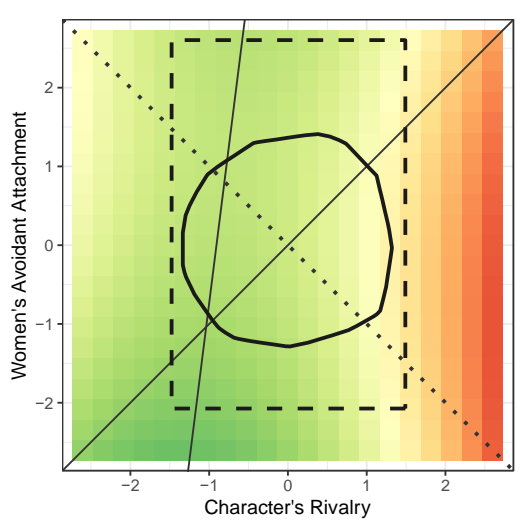

